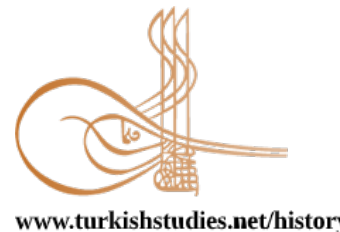

Turkish Studies - Historical Analysis

eISSN: 2667-5552

Research Article / Araştırma Makalesi

\title{
Gökhöyük Bağları Höyüğü’nden Bir Grup Demir Çağı Seramiği; Çanak
}

\author{
A Group of Iron Age Ceramics from Gökhöyük Bağları Mound; Bowls ${ }^{*}$
}

\author{
Ramazan Gündüz $^{* *}$ - Hasan Ali Erdoğan ${ }^{* * *}$
}

\begin{abstract}
Gökhöyük Bağları Mound is located in the Bağlar locality of Gökhöyük Neighborhood the district of Seydişehir in Konya province in the South of Central Anatolia. It is understood that the mound, the height of which is eleven meter from the lowland, is located on an area of approximately 29 hectares. A large number of terracotta artifacts were unearthed during the excavations carried out between 2002 and 2005 . The aim of this study is to introduce a group of terracotta pots selected within Iron Age ceramics which were excavated between 2002 and 2005 at Gökhöyük Bağları Mound, to develop a greater understanding of the position of the mound in central Anatolian chronology and to make a contribution to the regional evaluation of the mound. The artefacts exposed at Gökhöyük indicate that the inhabitants first settled at Gökhöyük lived here in the Pottery Neolithic Period. The geography of the mound draws attention with its proximity to cultivable land and water resources -right on the shore of lake Suğla called Trigotis in ancient times. In the mound, cultural continuity starting from the Neolithic Period to the Iron Age can be seen. This cultural continuity can be followed through the terracotta pottery obtained there. A group of bowls within the Iron Age ceramics exposed during the excavations at Gökhöyük Bağları Mound are the subject of this study. Of the subject of this study, all of the of the artefacts, dated to disparate periods of the Iron Age and considered as bowls are all wheel-made. After doing some research, it was comprehended that the bowls discussed here could be dated to $1200-400 \mathrm{BC}$. It was also identified that these bowls reflect the typical form characteristics of the middle Anatolian Iron Age ceramic tradition.
\end{abstract}

Structured Abstract: Gökhöyük Bağları Höyüğü is located in the Bağlar locality of Gökhöyük Neighborhood in the district of Seydişehir in Konya province in the South of Central Anatolia. It is understood that the mound, the height of which is eleven meter from the lowland, is located on an area of approximately 29 hectares. During the excavations carried out between 2002 and 2005, a large number of terracotta artifacts were unearthed. Iron Age culture layer was exposed just under the surface soil of the study area. Heavily damaged, architectural structures of partially preserved stone wall foundation represented the period. However, Iron Age cultures of early, middle and late stages could not be distinguished

\footnotetext{
* Bu çalışma yazarın, Selcuk Üniversitesi Sosyal Bilimler Enstitüsünde tamamladığı "Gökhöyük Bağları Höyüğü Demir Çağı Seramikleri” adlı Doktora tezinden yararlanılarak geliştirilmiş bir çalışmadır.

** Arş.Gör. Dr. Selçuk Üniversitesi Edebiyat Fakültesi Arkeoloji

Res. Asst. Dr. Selcuk University, Faculty of Letters, Archeology

ORCID 0000-0003-4113-119X

ramazangunduz@selcuk.edu.tr

${ }^{* * *}$ Dr. Selçuk Üniversitesi Edebiyat Fakültesi Arkeoloji Bölümü

Dr. Selcuk University, Faculty of Letters, Department of Archeology

ORCID 0000-0002-1795-4607

haerdogan@gmail.com

Cite as/ Atıf: Gündüz, R. \& Erdoğan, H. A. (2020). Gökhöyük Bağları Höyüğü’nden bir grup Demir Çağı seramiği;

çanak. Turkish Studies - History, 15(2), 477-498. https://dx.doi.org/10.29228/TurkishStudies.43207

Received/Geliş: 28 April/Nisan 2020

Checked by plagiarism software

Accepted/Kabul: 20 June/Haziran 2020

Published/Yayın: 25 June/Haziran 2020

Copyright (C INTAC LTD, Turkey

CC BY-NC 4.0
} 
architecturally. For this reason, understanding the chronological sequence of the mound was tried through its ceramics. Therefore, a group of ceramics, which we define as bowls, was focused in this study. Changes in the form, decoration and construction techniques of the ceramics were examined and they were compared (through relative chronology method) to those of leading key settlements on the Iron Age such as Gordion, Boğazköy, Kaman-Kalehöyük, Porsuk Höyük and Kınık Höyük. In this way, the ceramics were tried to date. Solid and/or liquid foods were most likely served in these vessels. They have also been called service pots in ceramic studies and their production is estimated to have been for daily use. These are divided into subtypes according to their features in their form and shapes of their mouth and body. All of the early stage bowls are rough and thick-walled vessels of potter's wheel. All the findings featuring the Early Iron Age (EIA) among the Gökhöyük Iron Age ceramics (IAC) are the bowls of thickened rims, conical bodies and wide mouths. Mouth diameters of the vessels vary between 24 and $47.6 \mathrm{~cm}$. It is evident that these rough containers are made of sloppy clay since they contain pieces of stones up to 2-3 millimeters in size. In addition, various organic property nodes observed on surface of the vessels support this opinion. There are also sub-types of these containers. The earliest examples of this type are of wide mouth, they have flattened mouth in the form of a tray, and their rims are thickened both inside and outside (T-shaped) (Fig.1, Drawing 1-4). It is understood from the intact examples that the vessels have conical bodies, which become narrow from mouth to pedestal. The containers, which narrow towards the pedestal, sit on the ring pedestal. The second group among the bowls dating to the early Iron Age composes of those that have slanted rims. Although they were made more elaborate than other early Iron Age samples, they are rough. Like other samples, these containers have conical bodies with a form narrowing from mouth to pedestal (Fig.2, Drawing 5-7). They sit on the ring pedestals similar to those in Type I, and their surface characteristics are not different from those of Type I. Similar samples to these bowls, which are dated to the early Iron Age, were seen in surface surveys in Konya and in the excavation in Kilise Tepe Level II, Kaman-Kalehöyük, Porsuk Höyük and Kınık Höyük. Gökhöyük Middle Iron Age bowls are smaller and more elaborately produced vessels compared to the early Iron Age samples. Stone pieces, which are common in early samples, are rare in this period. When the containers examined in terms of production technique, it is understood that all of them were wheel-made pots. Lining and polishing are common on the surfaces of the containers. Almost all of these containers have brownish surfaces of different light shades (Munsel 10 YR 6/4-6/3-5/2). The mouth diameters of the pieces in this group vary between 14.4 and $34.6 \mathrm{~cm}$. Of the bowls, Type 1 is the ones whose rims were thickened by rounding (Fig.3). Similar examples in terms of their forms are found in fire layer at Gordion/Yassihöyük dating to $800 \mathrm{~s} \mathrm{BC}$; in Oymaağaç Höyük dating to $900-330$ BC; at Porsuk Höyük dating to 900-550 BC; in Kınık Höyük dating to 11-9 century BC (Layer V); in Kilise Tepe, Level IIf dating to 750-650 BC. In the samples evaluated under Type 2, it is seen that the mouth of the container is thickened inward (Fig.4). Similar examples are dated at Porsuk Höyük 900-550 BC. While the vessels examined under Type 3 are similar to those in Type 2 in terms of their forms, they are distinguished from those in Type 2 by their thickened inverted rims. There are two bowls in Type 4, and they are separated from the others by their outward-pulled rims. Bowls dating to the late Iron Age are mostly by rounding of thickened rims, and they are hemispherical and/or conical vessels with shallow bodies (Fig.7, No: 1-13). Deep-formed and widemouthed bowls with high-ring pedestals seen in the early period are not encountered in this period. The majority of the vessels evaluated in this group are lined, and they have surfaces of different colors. It would not be wrong to hypothesize that late Iron Age bowls display more elaborate characteristics of production. As a result, this study contributed to the introduction of a group of Iron Age ceramics of Gökhöyük Bağları Mound, to the determination of chronological sequence of the mound and to the comparisons to be made between its regional contemporaries. The examinations on the bowls reveal that all three phases of the Iron Age (Early, Middle and Late) were settled in Gökhöyük. From this point of view, it would not be wrong to conclude that an uninterrupted life survived in Gökhöyük during the Iron Age and thus that there was a strong Iron Age settlement there. The fact that the bowls with conical bodied sustained their existence in every period suggests that traditions may have been transferred. However, more precise results about this period of the mound will be possible with new excavations on wider areas in the coming years.

Keywords: Bowl, Iron Age, Konya, Central Anatolia.

Öz: Gökhöyük Bağları Höyüğü Orta Anadolu'nun Güneyinde Konya ili Seydişehir ilçesi Gökhöyük Mahallesi Bağlar mevkiinde bulunmaktadır. Ova tabanından yüksekliği 11 metre olan höyüğün yaklaşık olarak 29 hektarlık bir alana oturduğu anlaşılmaktadır. Höyükte $2002-2005$ yılları arasında yapılan kurtarma kazılarında çok sayıda pişmiş toprak eser ortaya çıkarılmışıı. Bu çalışmanın amacı, Gökhöyük 
Bağları Höyüğü’nde yapılan arkeolojik çalışmalarda açığa çıkarılan Demir Çağı seramikleri içerisinden seçilen bir grup pişmiş toprak kabın tanıtımının yapılmasına, bunlar üzerinden höyüğün Orta Anadolu kronolojisindeki yerinin anlaşılmasına ve bölgesel açıdan değerlendirilmesinin yapılabilmesine yönelik katkı sağlamaktır. Höyükte açığa çıkarılan pişmiş toprak buluntulardan, Seramikli Neolitik Dönemden itibaren Gökhöyük sakinlerinin burada yaşadıkları anlaşılmaktadır. Höyüğün içinde bulunduğu coğrafya su kaynaklarına (Antik dönemde Trigotis olarak adlandırılan Suğla Gölü’nün hemen kıyısında) ve tarıma elverişli arazilere yakınlığı ile de dikkat çekmektedir. Höyükte Neolitik Dönemden başlayarak Demir Çăğ'na kadar devam eden bir kültürel devamlılık söz konusudur. Ele geçen pişmiş toprak çanak-çömlekten bu kültürel devamlılık takip edilebilmektedir. Burada yapılan kazılarda gün yüzüne çıkarılan Demir Çağı Seramikleri içerisindeki bir grup çanak çalışmanın konusunu oluşturmaktadır. Demir Çağı'nın farklı dönemlerine tarihlenen ve çanak olarak değerlendirilen bu buluntuların tamamı çark yapımıdır. Yapılan incelemeler sonrasında burada ele alınan çanakların MÖ 1200- 400 yılları arasına tarihlenebileceği anlaşılmıştır. Ayrıca, bu çanakların Orta Anadolu Demir Çağı seramik geleneğinin tipik form özelliklerini yansıttığı da tespit edilmiştir.

Anahtar Kelimeler: Çanak, Demir Çağı, Konya, Orta Anadolu.

\section{Giriş}

Yaklaşık olarak MÖ II. binin sonlarına kadar Anadolu'nun büyük bir kısmına hükmeden Hititlerin hükmettikleri bölgenin tamamında oluşturdukları merkezi otorite beraberinde tek düze bir kültür oluşturmuştur (Klengel, 2002: 213). Bu dönemde Anadolu'nun neredeyse tamamında görülen kültür, sanat izleri ve teknolojik açıdan birbirine benzeyen arkeolojik veriler bu düşünceyi desteklemektedir. Yaklaşık olarak MÖ 1200'lü yıllardan sonra, Hitit İmparatorluğu'nun Anadolu'da hâkimiyetini yitirmesi ile Anadolu'nun büyük bir bölümünde karışıklıkların olduğu anlaşılmaktadır (Macqueen, 2001: 170-175). Bu dönemde bazı büyük kentlerin terkedildiği ${ }^{1}$ veya yerle bir edildiği ileri sürülmektedir. $\mathrm{Bu}$ dönemin önemli yerleşmelerinden olan Alişar ve Alacahöyük'te yapılan çalışmalarda ortaya çıkarılan yangın tabakaları da bu düşünceyi desteklemektedir (Cline, 2014: 125). Anadolu'da merkezi otoritenin ortadan kalkmasının ardından ortaya çıkan Geç Hitit Krallıkları bölgesel hâkimiyetlerini ilan etmişlerdir (Hawkins, 2002: 410). Demir Çağı olarak da adlandırılan bu dönemde yeni yönetim ve yaşam tarzı, bölgesel, kültürel ve politik açıdan farklılıklar göstermektedir. Bölgesel farklılıkların görüldüğü bu dönemin izlerinin takip edilebildiği en önemli yerleşmeler arasında Gordion, Kaman-Kalehöyük, Boğazköy, Çadır Höyük ve Porsuk gibi Demir Çağ yerleşmeleri sayılabilir (Kealhofer ve Grave, 211: 418-442). Bu yerleşim yerlerinde yıllardır devam eden sistematik kazılarda elde edilen materyal kültürüne ait buluntular, Orta Anadolu bölgesinin Demir Çağı'ndaki kültürel oluşumun daha iyi anlaşılabilmesine olanak sağlamıştır. Orta Anadolu'da kazıları yapılan bu anahtar yerleşmeler bölgenin anlaşılmasını kolaylaştırırken, bölgenin güneyinde Konya Ovası'nın Toros dağları ile sınırlanan kesiminde herhangi bir sistematik kazının olmaması, bölgenin bu kesimi hakkında kesin yargılarda bulunulmasını zorlaştırmışıı². Gökhöyük Bağları Höyüğü'nde yapılan kazılarda ele geçen Demir Çağı Seramikleri (DÇS) bölge arkeolojisine katkı sağlamakta, bu çalışmanın konusunu oluşturan çanaklar da Gökhöyük Demir Çağı sakinlerinin günlük kullanım kapları hakkında önemli ipuçları sunmaktadır.

\footnotetext{
${ }^{1}$ Hitit devletine başkentlik yapan Hattuşa'da, Geç Tunç Çağından Erken Demir çağına geçiş süreci biraz daha karışıktır. Hermann Genz, Erken Demir Çağı'nın erken evresinde çanak çömlekte görülen Hitit geleneklerinden hareketle, son Hitit evresi ile Erken Demir Çağı'nın başlangıcı arasında herhangi bir boşluk olmadığını, yerleşimin kesintiye uğramadığını ileri sürmektedir (Genz, 2000: 111). Jürgen Seeher ise Hititlerin son döneminde önemini yitirerek terkedilen Hattuşaya MÖ 12. yüzyılda (Erken Demir Çağı'nda) yeni yerleşimcilerin geldiğini ileri sürmektedir (Seeher, 2010: 220).

${ }_{2} \mathrm{Bu}$ dönem ile ilgili bilgilerimiz bölgede yapılan yüzey araştırmalarından gelmekte olup Demir Çağı kültürleri hakkındaki değerlendirmeler de genelde yüzeyden toplanmış malzeme üzerinden yapılmaktadır.
} 


\section{Gökhöyük Bağları Höyüğü}

Gökhöyük Bağları Höyüğ̈̈3 , Konya'nın, Seydişehir ilçesinin Gökhöyük mahallesinde yer almaktadır (Gündüz, 2016: 44; 2019a: 62). Höyügün bulunduğu alana ulaşım Konya - Antalya Karayolunun Seydişehir ilçesi girişinden ayrılarak Seydişehir'den Bozkır'a ulaşımı sağlayan kara yolundan ilerlenerek Gökhöyük Mahallesinden sola dönerek sağlanır (Gündüz, 2019b: 207) Höyükte ilk çalışmalar Devlet Su İşleri 4. Bölge Müdürlügü̈nce açılan bir kanal çalışmasında tesadüfen arkeolojik eserlerin ortaya çıkmasıyla başlatılmıştır. Bu kanalın höyüğün doğu kısmına denk gelen çalışması sırasında bazı eserler ortaya çıkmıştır. Bunun üzerine çalışmalar durdurulmuş ve Konya Müzeler Müdürlüğü’ne durum bildirilmiștir (Gündüz, 2019a: 63; 2019c: 465). Bu aşamadan sonra Kültür Varlığı olarak tescil edilen Gökhöyük Bağları Höyüğ̈̈’nde ilk arkeolojik çalışmalar yapılmıştır. Yapılan ilk incelemelerde höyüğün doğu kısmında, tahminen elli metre boyunda on, on beş metre genişliğinde ve yaklaşık bir buçuk metre derinlikte bir tahribatın meydana geldiği anlaşılmıştır. Konya Müzeler Müdürlüğü tarafından görevlendirilen uzmanlar tarafından ilk çalışmalar 2002 yılında bu alanda başlatılmıştır. Gerçekleşen tahribatın öncesinde, höyügün bir süre mezarlık olarak kullanılmasından dolayı da tahribata maruz kaldığı ilk bulgular olarak tespit edilmiştir. Açılan bu mezarların tarım toprağının hemen altında en üst seviyede bulunan Demir Çağı yerleşmelerine ait mimari yapılarda ağır hasara sebep olduğu görülmüştür ${ }^{4}$. Gökhöyük’te kazılar 2002 - 2005 yılları boyunca devam etmiştir. Dört dönem devam eden kurtarma kazılarında açığa çıkarılan buluntular Konya Arkeoloji Müzesi'nde muhafaza altına alınmıştır. Bu eserler arasında bulunan Demir Çağı seramikleri "Gökhöyük Bağları Höyüğü Demir Çağı Seramikleri” başlıklı bir Doktora çalışması ile bilim dünyasına tanıtılmıştır. Bunun dışında yaptığımız çeşitli bilimsel çalışmalarda Gökhöyük seramikleri ayrıntılı olarak değerlendirilmeye çalışılmıştır. Gökhöyük buluntuları arasında en büyük çoğunluğu pişmiş toprak çanak-çömlek parçaları oluşturmaktadır ${ }^{5}$. Gökhöyük'te yapılan kazıların kurtarma kazıları mahiyetinde yapılması ve kazıyı yapan müze uzmanının statigrafiye uygun bir kazı yapamamasından dolayı, burada çalışılan seramikler bulundukları tabaka ile tam olarak ilişkilendirilememişlerdir. Kazılar sırasında tabakalar arası sınır belirlenmediği gibi herhangi bir C14 tarihlemesine de gidilmemiştir. Dolayısıyla burada çalışılan seramik buluntuların tarihlendirilmesinde Mutlak tarihlendirme söz konusu değildir. Çalışmaya konu seramiklerin form, dekorasyon ve yapım tekniğindeki değişimler incelenerek Demir Çağı için anahtar yerleşimlerin başında gelen Gordion, Boğazköy, KamanKalehöyük ve Porsuk Höyük yanında son dönemde kazıları yapılan Kınık Höyük gibi yerleşmelerle karşılaştırılarak tarihlendirilmeye çalışılmıştır.

\section{Gökhöyük Bağları Höyüğü Çanakları}

Çanak kelimesinin kökenine bakıldığında, Türk Dil Kurumunun 1976 yılında yayınlanan Zanaat Terimleri sözlüğüne göre, kil çadır direklerinin uçlarına geçirilen içi oyulmuş tahtalar çanak olarak adlandırılmaktadır (TDK, 1976: 33). Türk Dil Kurumu'nun güncel sözlüğünde ise çanak, toprak, metal vb. den yapılmış yayvan, çukurca kap olarak adlandırılmaktadır. Arkeoloji literatüründe ise açık formlar içerisinde değerlendirilen çanağın tanımı; çapı yüksekliğinin iki katından fazla olan kaplar olarak tarif edilmektedir (Ökse, 2012: 88). Gökhöyük'te yapılan kazılarda açığa çıkarılan ve açık formlu kaplar olarak ayrılan pişmiş toprak eserler arasında, ağız çap1 yüksekliğinin iki katından fazla olan kaplar çanak olarak değerlendirilmiştir. Çanaklar Gökhöyük Demir Çağı seramik buluntuları içerisinde önemli bir oranla temsil edilirler (Gündüz, 2019a: 84). Seramik çalışmalarında servis kabı olarak da adlandırıla gelen ve üretimleri günlük

\footnotetext{
3 ( Bu çalışmada kısaca GBH olarak da kullanılmıştır.)

${ }^{4}$ Büyük ihtimalle buraya mezar çukurlarını açanlar, kazı esnasında karşılaştıkları Demir Çağı’na tarihlenen mimari yapı duvarlarında bulunan düzgün kesme taşları sökerek, açtıkları mezar çukurlarını kapatmada veya mezarın etrafında tekrar kullanmış olmalıdırlar. Bu alanlarda çok sayıda Demir Çağı seramiği bulunduğu kazı raporlarında belirtilmiştir.

${ }^{5} \mathrm{Bu}$ çalışmada 2002 yılında Gökhöyükte başlayan kazı çalışmalarına sorumlu olarak atanan Ark. San. Tar. Muammer Koyuncu, Ark. Enver Akgün ve Gülseren Karakap gibi Müze uzmanları tarafından yazılan Gökhöyük Bağları Höyüğü Kurtarma Kazısı Sonuç Raporlarından faydalanılmıştır.
} 
kullanıma dönük olduğu tahmin edilen bu tür kaplarda büyük olasılıkla katı ve/veya sıvı gıdalar servis edilmiş olmalıdır. Bunlar kendi içinde form özelliklerine, ağız gövde biçimlerine ve/veya dönemlerine göre alt tiplere ayırılmaktadır. Burada incelenen kapların üretim tekniği incelendiğinde en erken örneklerden en geç örneklere kadar tamamının çarkta üretilmiş olduğu anlaşılmaktadır. Özellikle Erken Demir Çağı'na tarihlenen örneklerin yüzeyinde çark izleri bulunmaktadır. Çanaklardan erken dönemlere tarihlenenlerin tamamı kalın cidarlı olup kaba olarak nitelendirdiğimiz seramik grubuna girmektedir. Geç Demir Çağı'na tarihlenen örneklerin büyük çoğunluğu astarlı olup farklı renkte yüzeye sahiptirler. Bunların daha özenli bir yapım özelliği gösterdiğini söylemek yanlış olmaz.

\section{Erken Demir Çağı Çanakları}

Bu çalışmada, Gökhöyük Demir Çağı seramikleri (DÇS) içinde Erken Demir Çağı (EDÇ) özelliği gösteren 30 parçadan 7 örneğe yer verilmiştir ${ }^{6}$ (Lev. 1-2). Burada değerlendirilmeye alınan buluntuların tamamı kalınlaştırılmış ağız kenarlı konik gövdeli çanaklardır. Bu çanaklar büyük formlu olmaları ile dikkat çekmektedirler. Kapların ağız çapları 24 ile $47.6 \mathrm{~cm}$ arasında değişmektedir. Kaba nitelikli bu kapların özensiz hazırlanan kilden üretilmiş oldukları, bünyesinde bulunan taşcık gibi katkıların boyutlarının büyüklüğünün 2-3 milimetreyi bulmasından anlaşılmaktadır. Ayrıca kap üzerinde bulunan çeşitli organik katkı patlakları bu düşüncemizi desteklemektedir. Çanakların genel olan bu özellikleri dışında ağız-gövde biçimlerine göre kendi içinde alt tipleri de bulunmaktadır. Bu tipin en erken örnekleri yayvan ağızlı, ağız kısmı tabla şeklinde düzleştirilmiş, hem içe hem dişa doğru ( $T$ formlu) (Matsumura, 2005: 176, 280 ) kalınlaştırılmış ağız kenarlıdır. Ele geçen kısmen sağlam örneklerden kapların ağızdan kaideye doğru daralan konik gövdeli oldukları anlaşılmaktadır. Kaideye doğru daralan kap yaklaşık bir buçuk iki santim kadar yerden yükseltilmiş halka kaide üzerine oturmaktadır. Bu tip, dört adet örnek ile temsil edilmektedir (Lev.1, Çizim 1-4). Bunlar ağız kenarı-gövde parçasıdır. Orta sertlikte bir yapıya sahip kabın hamuru koyu grimsi bir renkte olup (Munsel2.5 Y 4/1) ${ }^{7}$ kilin içinde kireç, mika, taş ve kuvars gözle görülebilen katkılardandır (Gündüz, 2019b: 220 Çizim 7-9). EDÇ’ye tarihlenen çanaklar arasında ikinci grubu ise içe çekik ağız kenarlı (Çizim 5-7) çanaklar oluşturmaktadır (Lev.2). Bunlar diğer EDÇ örneklerine göre daha özenli yapılmış olsalar da genel ifadeyle kaba olarak değerlendirilebilirler. Bunlar da diğer örnekler gibi genelde grinin tonlarından oluşan koyu yüzlü bir görünüme sahiptirler (Gündüz, 2019b: 220 Çizim 10-12). EDÇ’ye tarihlene bu çanakların benzer örnekleri Kilise Tepe Level II. (Postgate ve Thomas, 2007: 121-164. Fig. 393/701), Kaman-Kalehöyük (Matsumura, 2005: Taf.14-19) gibi kazılarda Konya ve çevresinde yapılan yüzey araştırmalarında (Bahar ve Koçak, 2004: Çiz. 34, No.1-4, Çiz. 35, No. 2-3) karşımıza çıkmaktadır.

\section{Orta Demir Çağı Çanakları}

ODÇ dönem özelliği yansittı̆̆ tespit edilen çanaklardan $15^{\prime}$ i bu çalışma içerisinde incelenmiştir. $\mathrm{Bu}$ dönemde Orta Anadolu yerleşmelerinde hem boyalı hem de boyasız örnekler yaygın olarak görülürken, Gökhöyük Bağları Höyüğünde yaygın olarak boyasız gri ve grinin tonlarında yüzey rengine sahip çanaklar bulunmuştur. Erken dönemlerde Gökhöyük ile etkileşim içinde olduğu düşünülen Dağlık Kilikya bölgesi içinde kalan Kilise Tepe'de ise Orta Demir Çağına tarihlenen örneklerin çoğunluğunda boya bezeme bulunmaktadır ${ }^{8}$ (Postgate ve Thomas, 2007:161. Fig. 396/751-68). Gökhöyük ODÇ çanakları EDÇ örneklerine göre daha küçük çaplı ve daha özenli üretilmiş kaplardır. İncelenen kaplar üretim tekniği açısından ele alındığında tamamı çarkta üretilmiştir. Çanakların yüzeylerinde astar ve perdah uygulaması yaygındır. Bazı örneklerin ise

\footnotetext{
${ }^{6}$ Gökhöyük Bağları Höyüğü Erken Demir Çağı seramiği başlıklı çalışmada bu dönem seramiği ayrıntılı ele alındığından burada uzun uzadıya anlatılmamıştır. Ayrrıntılı bilgi için bkz. (Gündüz, 2019b: 204-222).

$7 \mathrm{Bu}$ çalışmadaki seramiklerin kil ve yüzey renkleri uluslararası kabul gören MunselColor Chart kullanılarak belirlenmiștir.

${ }^{8}$ Kilise Tepe Level IIf’de açığa çıkarılan çanaklar MÖ 750-650 aralığına tarihlendirilmiştir.
} 
düzgünleştirilmiş (smoothed) yüzeyli oldukları tespit edilmiştir (Lev 3. Çizim 6-9). Bu gruptaki parçaların ağız çapları 15 ile $33 \mathrm{~cm}$ arasında değişmektedir. Bu çanaklar kendi içinde ağız ve gövde özelliklerine göre alt gurulara ayrılmıştır. Bunlardan Tip 1 içinde değerlendirilen parçaların tamamının ağız kenarı yuvarlatılarak kalınlaştırılmıştır (Lev.3). İncelenen örneklerden çoğu kalın cidarlı, kaba seramiklerden oluşurken daha özenli yapılmış ve astarlanmış kaliteli örneklerde mevcuttur. Bu kapların neredeyse tamamı kahverenginin farklı açık tonlarında yüzeye sahiptir (Munsel 10 YR 6/4-6/3-5/2). Bunların yuvarlatılarak kalınlaştırılmış ağız kenarının hemen altında bulunan oluk bu grubu diğerlerinden ayırmaktadır. İncelenen kısmen sağlam örneklerden ağızdan kaideye doğru daralan bir forma sahip oldukları anlaşılmaktadır. Örneklerin genelde orta kalitede pişmiş olduğu, hamurlarında ise kireç, taş ve mika katk1 bulunduğu gözlemlenmiştir. Erken örneklerde sık görülen iri taşçık katkıya bu dönem örneklerinde pek rastlanmaz. Form açısından benzer örnekleri, Gordion/Yassıhöyük yangın tabakasına (MÖ 800’lere) (Sams, 1994: Fig. 21/518) Oymaağaç Höyükte MÖ 900-330 (Yılmaz, 2015: Lev. 17, Kat. No. 4.); Porsuk Höyükte MÖ 900550 ( Duprê, 1983: P1 62, Kat. No. 24.), Kınık Höyükte (MÖ 11-9. yüzyıl (Tabaka V) (Ergürer, 2016: Lev. 23, Kat. No. 194,); Kilise Tepe'de Level IIf'de (MÖ 750-650) (Postgate ve Thomas, 2007: 161. Fig. 396/751-68. ) tarihlenmektedir. Afyon ve çevresindeki araştırmalarda bulunan benzer örnekler de MÖ 8.-7. yüzyıla tarihlenmiştir (Bilgin, 2018: Lev.7, Kat. No.45.). Tip 2 altında değerlendirilen örneklerde kabın ağız kısmının içe doğru kalınlaştırılmış olduğu görülmektedir (Lev.4). İyi derecede pişirilmiş bu gurubun hamuru kireç, taş, şamot ve mika katkılıdır. Benzer örnekler Porsuk Höyük’te MÖ 900-550 tarihlenmektedir (Duprê, 1983: Pl 62, Kat. No. 24.). Tip 3 altında incelenen kaplar kalınlaştırılmış içe dönük ağız kenarlı olmalarıyla dikkat çekerler. Bunlar form olarak kısmen konik gövdeli ve yarı küresel gövdelilerden oluşmaktadırlar (Lev.5). Ağız çapları 21 ile $31.4 \mathrm{~cm}$ arasında değişmektedir. Örneklerin tamamı çarkta yapılmıştır. Fırınlamanın çok da iyi olmadığ örnekleri, Kaman-Kalehöyükte (Cronheit IIa6 IIc1) MÖ 8.-6. yüzyıla (Matsumura 2005, Taf. 159, No. KL87-3103.); Kınık Höyükte MÖ 6.-4. yüzy1l-Tabaka III'e tarihlenmektedir (Ergürer, 2016: Lev. 23, No. 199). Tip 4 içerisinde değerlendirilen ve iki örnekten oluşan grubumuz ise dişa çekik ağız kenarlı olmalarıyla dikkat çekmektedir. Ağız çapları yaklaşık olarak 15.4 ile $23.5 \mathrm{~cm}$ arasındadır. Bunların ikisi de ağız kenarı-gövde parçasıdır. Çark yapımı olan her iki örnek de dışa dönük ağızlı, ağızdan omuza keskin bir geçişe sahiptir. Ağzın hemen altında genişçe bir oluk bulunmaktadır. Koyu yüzlü, iyi pişirilmiş, sıkı dokulu, kabın hamurunda kireç, taş, kuvars ve mika katkı bulunmaktadır (Lev.6). Benzer örnekler Kınık Höyükte MÖ 8.-6. yüzyıl (Ergürer, 2016: Lev. 16, Kat. No. 129. ), Boğazköy'de MÖ 7.-5. yüzylla (Bossert, 2000: Taf 82/974), KamanKalehöyükte MÖ 600-580 ele geçmiştir (Matsumura, 2005: Taf. 156/KL 87-3798).

\section{Geç Demir Çağı Çanakları}

$\mathrm{Bu}$ grupta değerlendirilen çanaklar çoğunlukla yuvarlatılarak kalınlaştırılmış ağız kenarlı yarı küresel ve/veya konik gövdeli sığ kaplardır. Bunlar daha erken örneklerin form olarak devamı gibi görünse de genel özelliklerinde farklılıklar bulunmaktadır. Örneğin, incelenen parçalardan yola çıkarak, bu dönemde üretilen kapların form olarak küçüldügü görülmüştür. Buradaki örneklerin ağız çapı otuz santimetreyi geçmez. Erken dönemlerde görülen yüksek halka kaideli, derin formlu, yayvan ağızlı $45-50 \mathrm{~cm}$ kadar büyük ağız çaplı çanaklara bu dönemde rastlanmaz. Muhtemelen bunların kullanımı bu dönemde kalkmış olmalıdır. Ele geçen, kısmen sağlam örneklerden kaidesiz düz dipli çanakların kullanımın daha yaygın olduğu anlaşılmakla birlikte halka kaideli çanakların da varlığını sürdürdüğü görülmektedir. Bu döneme tarihlenen çanaklardan yalnız 13 örnek burada ele alınmıştır (Lev.7, No: 1-13). Parçalar yüzey özellikleri açısından incelendiğinde, tamamının astarlı olduğu anlaşılmaktadır. Erken örneklerde görülen mat ve koyu yüzeyin yerini daha parlak, gri ve kahverenginin tonları almıştır. Seramiklerin artık daha iyi pişirilmelerinin yanında kil hamurlarının da daha özenli hazırlandığg görülebilmektedir. Erken örneklerde görülen yoğun taşçık ve kireç katkıya pek rastlanmaz. Kireç katkının az kullanmasından kaynaklı erken dönemlerde kap üzerinde görülen kireç patlakları nadir görülür. $\mathrm{Bu}$ örnekler içinde yalnız 6-9. parçaların ağız 
kenarlarının diğerlerine göre farklı olduğu görülmektedir. Tarafımızdan Geç Demir Çağı'na tarihlenen bu kapların benzer örnekler, Boğazköy-Hattuşa'da MÖ 9.-6. y.y. (Genz, 2004: Taf. 40, Kat. No. 7.) Kaman-Kalehöyükte MÖ 6.-5. y.y. (Matsumura, 2005: Taf. 194, Kat. No. KL873162), Oymaağaç Höyükte MÖ 900-600/550'e (Y1lmaz, 2018: Lev. 5, Kat. No. 3.), Kınık Höyükte MÖ 6.-4. у.y. (Ergürer, 2016: Lev. 26, Kat. No. 225.) tarihlenen tabakalarda ele geçmiştir.

\section{Sonuc}

Sonuç olarak, Konya ili Seydişehir ilçe sınırları içerisinde bulunan Gökhöyük Bağları Höyügüu'nde 2002-2005 yılları arası yapılan kazılarda çok sayıda pişmiş toprak eser açığa çıkarılmıştır. Bu eserler arasında bulunan Demir Çağı seramiklerinin bir gurubunun tanıtımına, bunlar üzerinden höyügün kronolojik dizinin anlaşılmasına ve bölgesel kıyaslamaların yapılabilmesine yönelik yapılan bu çalışma, Demir Çağının Erken Orta ve Geç olarak tanımlanan her üç safhasının da Gökhöyükte yaşandığını ortaya koymaktadır. Buradan hareketle Demir Çağı’nda Gökhöyükte kesintisiz bir yaşamın sürdügünü, buna bağlı olarak da güçlü bir Demir Çağı yerleşiminin var olduğunu söylemek de yanlış olmayacaktır. Özellikle konik gövdeli çanakların her dönemde de varlıklarını sürdürmesi, seramik üretim geleneğinde de bir sürekliliğin olduğunu göstermektedir. Ayrıca Konya Ovası'nın Güney Batısında Demir Çağı'nda kullanılan çanakların form özellikleri açısından aynı dönemde yerleşim gören Kaman-Kalehöyük, Kınık Höyük, Porsuk Höyük gibi yerleşmelerle benzerliklerinin olması bölgesel ilişkilerin anlaşılmasına katkı sağlayacaktır. Her ne kadar üç evreye ait seramikler varsa da ODÇ ve GDÇ tarihlenen seramiklerin daha yoğun olduğu görülmüştür. Bu da ODÇ ve GDÇ dönemlerinde höyükteki iskânın daha yoğun olduğunu düşündürmektedir. Her ne kadar bu çalışmaya konu çanaklardan Gökhöyük Bağları Höyüğü'nün MÖ I. bini hakkında bilgiler edinsek de, höyüğün bu dönemi hakkında daha kesin sonuçlar yeni kazılar yapılınca mümkün olacaktır.

\section{Kaynakça}

Bahar, H. (1999). Demir Çă̆l’nda Konya ve Çevresi. Selçuk üniversitesi Yaşatma ve Geliştirme Vakfi Yayınları.

Bahar, H. ve Koçak, Ö. (2004). Eskiçağ Konya Araştırmaları 2. Kömen Yayınları.

Bilgin, P. K. (2018). Afyonkarahisar Yüzey Araştırmaları Işı̆̆ında İç Batı Anadolu Demir Çağı Seramiği. (Yüksek lisans tezi) Pamukkale Üniversitesi.

Bittel, K., Noumann, R. and Otto, H. (1941). Yazılıkaya Architectur, Felsbilder Inschriften und Kleınfunde.

Bossert, E. M. (2000). Die Keramik Phrygischer Zeit von Boğazköy: Fundeaus den Grabungskampagnen 1906, 1907, 1911, 1912, 1931-1939 und 1952-1960.

Bouthiller, C. (2014). Carlo Colantoni, Soe Debruyne, Claudia Glatz, Mette Marie Hald, David Heslop, Ekin Kozal, Bob Miller, Peter Popkin, Nicholas Postgate, Caroline S. Steele and Adam Stone Further work at Kilise Tepe, 2007-2011 Refining the Bronze to Iron Age transition, Anatolian Studes, 64, 95-161.

Cline, E., (2014). 1177 B.C. The Year Civilization Collapsed, Princeton University Press.

Durgu, F. (2013). Seyitömer Höyük MÖ I. Bin Gri Monokrom Seramikleri (Yüksek lisans tezi) Dumlupınar Üniversitesi.

Ergürer, H. (2016). Niğde Kınık Höyük Demir Çağı Seramikleri (Doktora Tezi) Atatürk Üniversitesi. 
Genz, H. (2000). The Early Iron Age in Central Anatolia in Light of Recent Research, The American Schools of Oriental Research. Near Eastern Archaeology, Vol. 63, No. 2, Ethnoarchaeology II. p. 111.

Genz, H. (2004). Büyükkaya: I. Die Keramik der Eisenzeit, Deutsches Achaologisches Institut, by, Verlag Philipp von Zabern.

Gunter, A. C. (1991). Gordion Excavations Final Reports (III). The Universtiy Museum of Archaeology and Antropology Universy of Pensilvania.

Gündüz, R. (2016). Neolitikten Kalkolitik Döneme Kadar Bozkır Ve Çevresindeki Yerleşmeler. Ed. Hasan Bahar, Hakan Kuyumcu, Çağatay Benhür, Hatice Gül Küçükbezci, Murat Turgut, Fatih Numan Küçükballı Geçmişten Günümüze Bozkır Sempozyum Kitabı. (s.3348)

Gündüz, R. (2019a). Gökhöyük Bağları Höyüğü Demir Çağı Seramiği. (Doktora Tezi). Selçuk Üniversitesi.

Gündüz, R. (2019b). Gökhöyük Bağları Höyüğünden Erken Demir Çağı Seramiği. Karadeniz Uluslararası Bilimsel Dergi, 42, 204-222. doi: 10.17498/kdeniz

Gündüz, R. (2019c) Gökhöyük Bağları Höyüğünden Bir Grup Akhaimenid Kase. (Ed.) A. Erön \& E. Erdan, Doğudan Batıya 70. Yaşında Serap Yaylalı'ya Sunulan Yazılar. (s. 465-484) Bilgin Kültür Sanat Yay.

Hawkins, J. D. (2002). "Büyük İmparatorluğun Mirasçıları I: Anadolu Ve Kuzey Suriye'de Geç Hitit Krallıkları Tarihçesine Genel Bakış (Yaklaşık MÖ. 1180-700)", Hititler ve Hitit İmparatoluğu:1000 Tanrılı Halk Sergi Kataloğu, Ed.: W, Jacob, Kunst-und Ausstellungshalle der Bundesrepublik Deu, ss. 410 - 412.

Henrickson, C. R. (1994). Continuity and Discontinuity in the Ceramic Tradition of Gordion During the Iron Age. Anatolian Iron Ages 3, (s.95-120). The British Institute Of Archaeology.

Kealhofer, L. and Grave, P. (2011). Chronology and Geography. The Iron Age on the Central Anatolian Plateau, Steadman Chapter 18, (s.415-442). Oxford University Press.

Klengel, H. (2002). Hitit Tarihi. Hititler ve Hitit Imparatoluğu:1000 Tanrılı Halk Sergi Kataloğu, Ed.: W, Jacob, (s.412 - 420) Kunst-und Ausstellungshalle der Bundesrepublik Deu.

Koyuncu, M. Akgün, E. Karakap, G. (2002). Gökhöyük Bağları Höyüğü Kurtarma Kazısı Sonuç Raporlar1.

Macqueen, J. G., (2001). Hititler ve Hitit Çağında Anadolu, (Çev.) E. Davutoğlu, Arkadaş Yayınlar1.

Matsumura, K. (2005). Die Eisenzeitliche keramik in Zentralanatolien aufgrund der keramik in Kaman-Kalehöyük. (Doktora Tezi). Freie Universitet.

Munsell (2013). Munsell Soil Color Charts. U.S. Gov. Print.

Ökse, A.T. (2012). Önasya Arkeolojisinde Çanak Çömlek-Teknik özellikler, Biçimler-Türkçe, İngilizce, Almanca ve Fransızca Terimler, Arkeoloji ve Sanat Yayınları.

Postgate, J. N., Thomas, D. C. (2007). Excavations at Kilise Tepe, 1994-1998: From Bronze Age to Byzantine in Western Cilicia. 2 vols. Monograph 30. McDonald Institute/BIA

Sams, G. K. (1994). The Early Phrygian Pottery, The Gordion Excavations, 1950-1973, Final Reports, Volume IV, Text and Illustrations, The University Museum University of Pennsylvania 
Seeher J. (2010). After the Em pire: Observations on the Early Iron Age in Central Anatolia, (Ed.) I. Singer İpamati Kistamati Pari Tumatimis Luwian And Hittite Studies Presented To J. David Hawkins On The Occasion Of His 70th Birthday s. (220-229). Emery and Claire Yass Publications in Archaeology.

Yılmaz, M. A. (2015). Vezirköprü Oymaağaç Höyük Demir Çağ Seramikleri, (Doktora Tezi). Atatürk Üniversitesi.

(1.1) Erken Demir Çağı Çanakları

(1.2)

\begin{tabular}{|c|c|c|c|c|c|c|c|c|}
\hline \multirow[t]{2}{*}{1} & Kazı Buluntu No. & Mal & Form & Bezeme & $\begin{array}{c}\text { Hamur } \\
\text { Rengi }\end{array}$ & Astar Rengi & $\begin{array}{c}\text { İç } \\
\text { Renk }\end{array}$ & A.Çap \\
\hline & 20E/K10/T1/660 & İyi & Çanak & - & $10 \mathrm{YR} 5 / 2$ & Gley 1-4/N & - & 31.2 \\
\hline & Tanım & \multicolumn{7}{|c|}{$\begin{array}{l}\mathrm{T} \text { formlu Ağız kenarı-gövde parçasıdır. Ağzın hemen altında oluk bezeme } \\
\text { belirgindir. Dış yüzeyi düzleştirilmiş, iç yüzeyi açkılıdır. İyi pişmiş, kabın hamuru } \\
\text { kireç, mika ve taş katkılıdır. }\end{array}$} \\
\hline & Referans-Dönem & \multirow{2}{*}{\multicolumn{7}{|c|}{$\begin{array}{l}\text { Henrickson 1994, Fig. 10.2.1, (a) Fig. 10.2.2. (1-m) YHSS 8, (Geç Bronz Çă̆ı); } \\
\text { Bouthiller vd. 2014, Fig. 51, c, Fig. 46, c,f,k, Fig. 48, (level III); Ergürer 2016, } \\
\text { Lev. 4, No. 27, Lev. 5, No. 35-37, 43 (MÖ 11.-9. yüzyll); Y1lmaz 2015, Lev 20, } \\
\text { No. 5 (MÖ 1125-900); Matsumura 2005, Taf. 3, KL 92-M150, Taf. 3, KL 94- } \\
\text { M107, Taf. 3, KL 96-M58 (Chronheit III12-13). }\end{array}$}} \\
\hline & ö 13.-11. yüzyıl & & & & & & & \\
\hline
\end{tabular}

\begin{tabular}{|c|c|c|c|c|c|c|c|c|}
\hline \multirow[t]{2}{*}{2} & Kazı Buluntu No. & Mal & Form & Bezeme & $\begin{array}{c}\text { Hamur } \\
\text { Rengi }\end{array}$ & Astar Rengi & İç Renk & A.Çap \\
\hline & $16 \mathrm{G} / \mathrm{K} 44 / \mathrm{T} 2 / 365$ & Kaba & Canak & - & 2.5 Y $5 / 2$ & 7.5 YR $6 / 4$ & - & 32 \\
\hline & Tanım & \multicolumn{7}{|c|}{$\begin{array}{l}\text { Ağız kısmından kaideye kadar sağlam ele geçen nadir örneklerdendir. T formlu } \\
\text { ağzın hemen altında oluk bezeme belirgindir. Halka kaidelidir. Diş yüzeyi } \\
\text { düzleştirilmiş, iç yüzeyi açkılldır. İyi pişmiş, kabın hamuru kireç vemika katkılıdır. }\end{array}$} \\
\hline & Referans-Dönem & \multirow{2}{*}{\multicolumn{7}{|c|}{$\begin{array}{l}\text { Henrickson 1994, Fig. 10.2.1, (a) Fig. 10.2.2. (1-m) YHSS 8, (Geç Bronz Çă̆); } \\
\text { Bouthiller vd. 2014, Fig. 51, c, Fig. 46, c,f,k, Fig. 48, (level III); Ergürer 2016, } \\
\text { Lev. 4, No. 27, Lev. 5, No. 35-37, 43 (MÖ 11.-9. yüzyll); Y1lmaz 2015, Lev 20, } \\
\text { No. } 5 \text { (MÖ 1125-900); Matsumura 2005, Taf. 3, KL 92-M150, Taf. 3, KL 94- } \\
\text { M107. Taf. 3. KL 96-M58 (Chronheit III12-13). }\end{array}$}} \\
\hline & MÖ 13.-11. yüzyll & & & & & & & \\
\hline
\end{tabular}

\begin{tabular}{|c|c|c|c|c|c|c|c|c|}
\hline \multirow[t]{2}{*}{3} & Kazi Buluntu No. & Mal & Form & Bezeme & Hamur Rengi & $\begin{array}{l}\text { Astar } \\
\text { Rengi }\end{array}$ & İç Renk & A.Çap \\
\hline & $16 \mathrm{G} / \mathrm{K} 44 / \mathrm{T} 1 / 355$ & Kaba & Çanak & - & 7.5 YR 5/3 & 5 YR $6 / 4$ & 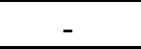 & 40.2 \\
\hline & Tanım & \multicolumn{7}{|c|}{$\begin{array}{l}\mathrm{T} \text { formlu ağız kenarı-gövde parçasıdır. Ağzın hemen altında oluk bezeme } \\
\text { belirgindir. Dış yüzeyi düzleştirilmiş, iç yüzeyi açkıılıdır. İyi pişmiş, kabın hamuru } \\
\text { kireç, mika ve taş katkılıdır. }\end{array}$} \\
\hline & Referans-Dönem & \multirow{2}{*}{\multicolumn{7}{|c|}{$\begin{array}{l}\text { Henrickson 1994, Fig. 10.2.1, (a) Fig. 10.2.2. (1-m) YHSS 8, (Geç Bronz Çă̆l); } \\
\text { Bouthiller vd. 2014, Fig. 51, c, Fig. 46, c,f,k, Fig. 48, (level III); Ergürer 2016, } \\
\text { Lev. 4, No. 27, Lev. 5, No. 35-37, 43 (MÖ 11.-9. yüzy1l); Y1lmaz 2015, Lev 20, } \\
\text { No. } 5 \text { (MÖ 1125-900); Matsumura 2005, Taf. 3, KL 92-M150, Taf. 3, KL 94- } \\
\text { M107, Taf. 3, KL 96-M58 (Chronheit III12-13). }\end{array}$}} \\
\hline & Ö 13.-11. yüzyıl & & & & & & & \\
\hline
\end{tabular}

\begin{tabular}{|c|c|c|c|c|c|c|c|c|}
\hline 4 & Kazı Buluntu No. & Mal & Form & Bezeme & $\begin{array}{c}\text { Hamur } \\
\text { Rengi }\end{array}$ & $\begin{array}{c}\text { Astar } \\
\text { Rengi }\end{array}$ & İç Renk & A.Çap \\
\hline
\end{tabular}




\begin{tabular}{|c|c|c|c|c|c|c|c|}
\hline 18/F K3/ T1/ 614 & İyi & Çanak & - & $2.5 \mathrm{Y} \mathrm{4/1}$ & $2.5 \mathrm{Y} \mathrm{5/1}$ & - & 24 \\
\hline Tanım & \multicolumn{7}{|c|}{$\begin{array}{l}\mathrm{T} \text { formlu ağı kenarı-gövde parçasıdır. Ağzın hemen altında oluk bezeme } \\
\text { belirgindir. Dış yüzeyi düzleştirilmiş, iç yüzeyi açkılıdır. İyi pişmiş, kabın hamuru } \\
\text { kireç, mika ve taş katkılıdır. }\end{array}$} \\
\hline Referans-Dönem & \multirow{2}{*}{\multicolumn{7}{|c|}{$\begin{array}{l}\text { Henrickson 1994, Fig. 10.2.1, (a) Fig. 10.2.2. (1-m) YHSS 8, (Geç Bronz Çağı); } \\
\text { Bouthiller vd. 2014, Fig. 51, c, Fig. 46, c,f,k, Fig. 48, (level III); Ergürer 2016, } \\
\text { Lev. 4, No. 27, Lev. 5, No. 35-37, } 43 \text { (MÖ 11.-9. yüzy1l); Y1lmaz 2015, Lev 20, } \\
\text { No. } 5 \text { (MÖ 1125-900); Matsumura 2005, Taf. 3, KL 92-M150, Taf. 3, KL 94- } \\
\text { M107, Taf. 3, KL 96-M58 (Chronheit III12-13). }\end{array}$}} \\
\hline MÖ 13.-11. yüzyıl & & & & & & & \\
\hline
\end{tabular}

\section{(1.2.) Erken Demir Çağı Çanakları}

\begin{tabular}{|c|c|c|c|c|c|c|c|c|}
\hline \multirow[t]{2}{*}{5} & Kazı Buluntu No. & Mal & Form & Bezeme & $\begin{array}{c}\text { Hamur } \\
\text { Rengi }\end{array}$ & $\begin{array}{l}\text { Astar } \\
\text { Rengi }\end{array}$ & $\begin{array}{c}\text { İç } \\
\text { Renk }\end{array}$ & A.Çap \\
\hline & 17F-E/K45/T1/841 & Kaba & Çan & - & $10 \mathrm{YR} 4 / 3$ & $5 \mathrm{YR} 5 / 3$ & - & 32 \\
\hline & Tanım & \multicolumn{7}{|c|}{$\begin{array}{l}\text { Ağız kenarı-gövde parçasıdır. İçe çekik ağızlı olup ağızdan kaideye daralan konik } \\
\text { bir gövdeye sahiptir. Orta pişmiş, kabın hamuru kireç, mika ve şamot katkılıdır. }\end{array}$} \\
\hline & ferans-Dönem & \multirow{2}{*}{\multicolumn{7}{|c|}{$\begin{array}{l}\text { Duprê 1983, P1.8, No. 39-45, (Niveau V); Bouthiller vd. 2014, Fig. 46, c, (level } \\
\text { III); Matsumura 2005, Taf. 4, KL 94-M56, KL 92-M225, Taf. 4, KL 95-M370, } \\
\text { (Chronheit III12-13). }\end{array}$}} \\
\hline & 11.-9. & & & & & & & \\
\hline
\end{tabular}

\begin{tabular}{|c|c|c|c|c|c|c|c|c|}
\hline \multirow[t]{2}{*}{6} & Kazı Buluntu No. & Mal & Form & Bezeme & $\begin{array}{c}\text { Hamur } \\
\text { Rengi }\end{array}$ & $\begin{array}{l}\text { Astar } \\
\text { Rengi }\end{array}$ & $\begin{array}{c}\text { İç } \\
\text { Renk }\end{array}$ & A.Çap \\
\hline & 19E/K39/T5/281 & Kaba & Çanak & & 7.5 YR 4/6 & 2.5 YR $6 / 6$ & & 47.6 \\
\hline & Tanım & \multicolumn{7}{|c|}{$\begin{array}{l}\text { Ağız kenarı-gövde parçasıdır. İçe çekik ağızlı olup ağızdan kaideye daralan konik } \\
\text { bir gövdeye sahiptir. İyi pişmiș, kabın hamuru kireç, şamot ve mika katkılıdır. }\end{array}$} \\
\hline & Referans-Dönem & \multicolumn{7}{|c|}{$\begin{array}{l}\text { Duprê 1983, P1.8, No. 39-45, (Niveau V); Bouthiller vd. 2014, Fig. 46, c, (level } \\
\text { III); Matsumura 2005, Taf. 4, KL 94-M56, KL 92-M225, Taf. 4, KL 95-M370, } \\
\text { (Chronheit III12-13). }\end{array}$} \\
\hline
\end{tabular}

\begin{tabular}{|c|c|c|c|c|c|c|c|c|}
\hline \multirow[t]{2}{*}{7} & Kazı Buluntu No. & Mal & Form & Bezeme & $\begin{array}{c}\text { Hamur } \\
\text { Rengi }\end{array}$ & $\begin{array}{l}\text { Astar } \\
\text { Rengi }\end{array}$ & İç Renk & A.Çap \\
\hline & 13G/K30/T6/868 & İyi & Çanak & - & 5 Y $5 / 1$ & 10 YR $6 / 4$ & - & 29.2 \\
\hline & Tanım & \multicolumn{7}{|c|}{$\begin{array}{l}\text { Ağız kısmından kaideye kadar sağlam ele geçen nadir örneklerdendir. İçe çekik } \\
\text { ağızlı olup ağızdan kaideye daralan konik bir gövdeye sahiptir. Halka kaidelidir. } \\
\text { İyi pişmiş, kabın hamuru kireç, mika ve taş katkılıdır. }\end{array}$} \\
\hline & Referans-Dönem & \multicolumn{7}{|c|}{$\begin{array}{l}\text { Duprê 1983, Pl.8, No. 39-45, (Niveau V); Bouthiller vd. 2014, Fig. 46, c, (level } \\
\text { III); Matsumura 2005, Taf. 4, KL 94-M56, KL 92-M225, Taf. 4, KL 95-M370, } \\
\text { (Chronheit III12-13). }\end{array}$} \\
\hline
\end{tabular}

\section{(2.1.) Orta Demir Çağı Çanakları}

\begin{tabular}{|c|c|c|c|c|c|c|c|c|}
\hline 1 & Kazi Buluntu No. & Mal & Form & Bezeme & $\begin{array}{c}\text { Hamur } \\
\text { Rengi }\end{array}$ & $\begin{array}{l}\text { Astar } \\
\text { Rengi }\end{array}$ & İç Renk & A.Çap \\
\hline & $17-18 \mathrm{G} / \mathrm{K} 49 / \mathrm{T} 2 / 45$ & İyi & Çanak & - & $2.5 \mathrm{Y} 5 / 1$ & $10 \mathrm{YR} 6 / 3$ & - & 16 \\
\hline & Tanım & \multicolumn{7}{|c|}{$\begin{array}{l}\text { Ağız kenarı-gövde parçasıdır. Yuvarlatılarak kalınlaştırılmış ağız kenarlı, gövdeden } \\
\text { kaideye daralan konik gövdeli, benzer örnekleri halka kaidelidir. Kaba kalın cidarlı } \\
\text { bir forma sahiptir. Orta pişmiş, kabın hamuru şamot, taş ve mika katkıllıdır. }\end{array}$} \\
\hline & Referans-Dönem & \multicolumn{7}{|c|}{ Sams 1994, Fig. 24/518; Genz 2004, Taf. 40, Kat. No. 7, (MÖ 9.-6. yüzy1l); Yılmaz } \\
\hline
\end{tabular}


MÖ 9.-6. yüzyll

2018, Lev. 5, Kat. No. 3, (MÖ 900-600/550); Ergürer 2016, Lev. 23, Kat. No. 194, (MÖ 11-9. yüzyıl (Tabaka V); Matsumura 2005, Taf. 194, Kat. No. KL87-3162, (MÖ 6.-5. Yüzyıl).

\begin{tabular}{|c|c|c|c|c|c|c|c|c|}
\hline \multirow[t]{2}{*}{2} & Kazı Buluntu No. & Mal & Form & Bezeme & $\begin{array}{c}\text { Hamur } \\
\text { Rengi }\end{array}$ & $\begin{array}{l}\text { Astar } \\
\text { Rengi }\end{array}$ & İç Renk & A.Çap \\
\hline & 19-20D/K14/T1/969 & İyi & Çanak & - & $10 \mathrm{YR} 3 / 1$ & $10 \mathrm{YR} 6 / 4$ & - & 33 \\
\hline & Tanım & \multicolumn{7}{|c|}{$\begin{array}{l}\text { Ağız kenarı-gövde parçasıdır. Yuvarlatılarak kalınlaştırılmış ağız kenarlı, gövdeden } \\
\text { kaideye daralan konik gövdeli olup benzer örnekler halka kaidelidir. Orta pişmiş, } \\
\text { kabın hamuru şamot, taş ve mika katkılıdır. }\end{array}$} \\
\hline & Referans-Dönem & \multirow{2}{*}{\multicolumn{7}{|c|}{$\begin{array}{l}\text { Sams 1994, Fig. 24/518; Genz 2004, Taf. 40, Kat. No. 7, (MÖ 9.-6. yüzy1l); Y1lmaz } \\
\text { 2018, Lev. 5, Kat. No. 3, (MÖ 900-600/550); Ergürer 2016, Lev. 23, Kat. No. 194, } \\
\text { (MÖ 11-9. yüzy1l (Tabaka V)); Matsumura 2005, Taf. 194, Kat. No. KL87-3162, } \\
\text { (MÖ 6.-5. Yüzyıl). }\end{array}$}} \\
\hline & MÖ 9.-6. yüzyıl & & & & & & & \\
\hline
\end{tabular}

\begin{tabular}{|c|c|c|c|c|c|c|c|c|}
\hline 3 & Kazı Buluntu No. & Mal & Form & Bezeme & $\begin{array}{c}\text { Hamur } \\
\text { Rengi }\end{array}$ & $\begin{array}{l}\text { Astar } \\
\text { Rengi }\end{array}$ & İç Renk & A.Çap \\
\hline & 19-20D/K14/T1/984 & İyi & Çanak & - & $10 \mathrm{YR} 6 / 4$ & $10 \mathrm{YR} 6 / 4$ & - & 23 \\
\hline & Tanım & \multicolumn{7}{|c|}{$\begin{array}{l}\text { Ağız kenarı-gövde parçasıdır. Yuvarlatılarak kalınlaştırılmış ağız kenarlı, gövdeden } \\
\text { kaideye daralan konik gövdeli olup benzer örnekler halka kaidelidir. Orta pişmiş, } \\
\text { kabın hamuru şamot, taş ve mika katkılıdır. }\end{array}$} \\
\hline & Referans-Dönem & \multirow{2}{*}{\multicolumn{7}{|c|}{$\begin{array}{l}\text { Sams 1994, Fig. 24/518; Genz 2004, Taf. 40, Kat. No. 7, (MÖ 9.-6. yüzyıl); Y1lmaz } \\
\text { 2018, Lev. 5, Kat. No. 3, (MÖ 900-600/550); Ergürer 2016, Lev. 23, Kat. No. 194, } \\
\text { (MÖ 11-9. yüzy1l (Tabaka V)); Matsumura 2005, Taf. 194, Kat. No. KL87-3162, } \\
\text { (MÖ 6.-5. Yüzy1l). }\end{array}$}} \\
\hline & MÖ 9.-6. yüzyıl & & & & & & & \\
\hline
\end{tabular}

\begin{tabular}{|c|c|c|c|c|c|c|c|c|}
\hline 4 & Kazı Buluntu No. & Mal & Form & Bezeme & $\begin{array}{c}\text { Hamur } \\
\text { Rengi }\end{array}$ & $\begin{array}{l}\text { Astar } \\
\text { Rengi }\end{array}$ & İç Renk & A.Çap \\
\hline & 19-20D/K14/T1/967 & İyi & Çanak & & $7.5 \mathrm{YR} 4 / 3$ & $10 \mathrm{YR} 3 / 1$ & & 28 \\
\hline & Tanım & \multicolumn{7}{|c|}{$\begin{array}{l}\text { Ağız kenarı-gövde parçasıdır. Yuvarlatılarak kalınlaştırılmış ağız kenarlı, } \\
\text { gövdeden kaideye daralan konik gövdeli olup benzer örnekler halka kaidelidir. } \\
\text { Orta pişmiş, kabın hamuru şamot, taş ve mika katkılıdır. }\end{array}$} \\
\hline & Referans-Dönem & \multirow{2}{*}{\multicolumn{7}{|c|}{$\begin{array}{l}\text { Sams 1994, Fig. 24/518; Genz 2004, Taf. 40, Kat. No. 7, (MÖ 9.-6. yüzy1l); } \\
\text { Y1lmaz 2018, Lev. 5, Kat. No. 3, (MÖ 900-600/550); Ergürer 2016, Lev. 23, Kat. } \\
\text { No. 194, (MÖ 11-9. yüzy1l (Tabaka V)); Matsumura 2005, Taf. 194, Kat. No. } \\
\text { KL87-3162, (MÖ 6.-5. Yüzy1l). }\end{array}$}} \\
\hline & MÖ 9.-6. yüzyıl & & & & & & & \\
\hline
\end{tabular}

\begin{tabular}{|c|c|c|c|c|c|c|c|c|}
\hline 5 & Kazı Buluntu No. & Mal & Form & Bezeme & $\begin{array}{c}\text { Hamur } \\
\text { Rengi }\end{array}$ & $\begin{array}{l}\text { Astar } \\
\text { Rengi } \\
\end{array}$ & İç Renk & A.Çap \\
\hline & 18F/K3/T1/602 & İyi & Çanak & - & $2.5 \mathrm{Y} 3 / 1$ & $10 \mathrm{YR} 5 / 2$ & - & 23.4 \\
\hline & Tanım & \multicolumn{7}{|c|}{$\begin{array}{l}\text { Ağız kenarı-gövde parçasıdır. Yuvarlatılarak kalınlaştırılmış ağız kenarlı, } \\
\text { gövdeden kaideye daralan konik gövdeli olup benzer örnekler halka kaidelidir. } \\
\text { Orta pişmiş, kabın hamuru şamot, taş ve mika katkılıdır. }\end{array}$} \\
\hline & Referans-Dönem & \multirow{2}{*}{\multicolumn{7}{|c|}{$\begin{array}{l}\text { Sams 1994, Fig. 24/518; Genz 2004, Taf. 40, Kat. No. 7, (MÖ 9.-6. yüzy1l); } \\
\text { Y1lmaz 2018, Lev. 5, Kat. No. 3, (MÖ 900-600/550); Ergürer 2016, Lev. 23, Kat. } \\
\text { No. 194, (MÖ 11-9. yüzy1l (Tabaka V)); Matsumura 2005, Taf. 194, Kat. No. } \\
\text { KL87-3162, (MÖ 6.-5. Yüzy1l). }\end{array}$}} \\
\hline & MÖ 9.-6. yüzyıl & & & & & & & \\
\hline
\end{tabular}

\section{(2.2.) Orta Demir Çağı Çanakları}




\begin{tabular}{|c|c|c|c|c|c|c|c|c|}
\hline \multirow[t]{2}{*}{6} & Kazı Buluntu No. & Mal & Form & Bezeme & $\begin{array}{l}\text { Hamur } \\
\text { Rengi }\end{array}$ & Dış Rengi & İç Renk & A.Çap \\
\hline & $17-18 \mathrm{G} / \mathrm{K} 49 / \mathrm{T} 2 / 13$ & İyi & Çanak & - & Gley $16 / \mathrm{N}$ & Gley $15 / \mathrm{N}$ & - & 22 \\
\hline & Tanım & \multicolumn{7}{|c|}{$\begin{array}{l}\text { Ağız kenarı-gövde parçasıdır. İçe doğru kalınlaştırılmış ağızlı, içe dönük kenarlı ve } \\
\text { konik gövdelidir. İyi pişmiş, kabın hamuru kireç ve mika katkılıdır. }\end{array}$} \\
\hline & Referans-Dönem & \multirow{2}{*}{\multicolumn{7}{|c|}{$\begin{array}{l}\text { Durgu 2013, Lev. XIX, Kat No. 31, (MÖ 5.-4. yüzy1l); Bilgin 2018, Lev.7, Kat. } \\
\text { No.45, (MÖ 8.-7. yüzy1l); Polat, 2002, Lev. 43, Çiz. B12, (MÖ geç 6.- erken 5. } \\
\text { yüzy1); Y1lmaz 2015, Lev. 17, Kat. No. 4, (MÖ 900-330); Duprê 1983, Pl 62, Kat. } \\
\text { No. 24, (MÖ 900-550). }\end{array}$}} \\
\hline & MÖ 9.-6. yüzyıl & & & & & & & \\
\hline
\end{tabular}

\begin{tabular}{|c|c|c|c|c|c|c|c|c|}
\hline \multirow[t]{2}{*}{7} & Kazı Buluntu No. & Mal & Form & Bezeme & $\begin{array}{c}\text { Hamur } \\
\text { Rengi }\end{array}$ & Dış Rengi & İç Renk & A.Çap \\
\hline & 19-20D/K14/T1/973 & İyi & Çanak & - & Gley $15 / \mathrm{N}$ & Gley $14 / \mathrm{N}$ & - & 16 \\
\hline & Tanım & \multicolumn{7}{|c|}{$\begin{array}{l}\text { Ağız kenarı-gövde parçasıdır. İçe doğru kalınlaştırılmış ağızlı, içe dönük kenarlı } \\
\text { ve konik gövdelidir. İyi pişmiş, kabın hamuru kireç ve mika katkılıdır. }\end{array}$} \\
\hline & Referans-Dönem & \multirow{2}{*}{\multicolumn{7}{|c|}{$\begin{array}{l}\text { Durgu 2013, Lev. XIX, Kat No. 31, (MÖ 5.-4. yüzy1l); Bilgin 2018, Lev.7, Kat. } \\
\text { No.45, (MÖ 8.-7. yüzy1l); Polat, 2002, Lev. 43, Chiz. B12, (MÖ geç 6.- erken 5. } \\
\text { yüzy1l); Y1lmaz 2015, Lev. 17, Kat. No. 4, (MÖ 900-330); Duprê 1983, Pl 62, } \\
\text { Kat. No. 24, (MÖ 900-550). }\end{array}$}} \\
\hline & MÖ 8.-5. yüzyıl & & & & & & & \\
\hline
\end{tabular}

\begin{tabular}{|c|c|c|c|c|c|c|c|c|}
\hline \multirow[t]{2}{*}{8} & Kazı Buluntu No. & Mal & Form & Bezeme & $\begin{array}{c}\text { Hamur } \\
\text { Rengi }\end{array}$ & Dış Rengi & İç Renk & A.Çap \\
\hline & 19-20DE/K20/T1/456 & İyi & Çanak & - & 10 YR $6 / 3$ & 10 YR $6 / 2$ & - & 27.8 \\
\hline & Tanım & \multicolumn{7}{|c|}{$\begin{array}{l}\text { Ağız kenarı-gövde parçasıdır. İçe doğru kalınlaştırılmış ağızlı, içe dönük kenarlı } \\
\text { ve konik gövdelidir. İyi pişmiş, kabın hamuru kireç ve mika katkılıdır. }\end{array}$} \\
\hline & Referans-Dönem & \multirow{2}{*}{\multicolumn{7}{|c|}{$\begin{array}{l}\text { Durgu 2013, Lev. XIX, Kat No. 31, (MÖ 5.-4. yüzy1l); Bilgin 2018, Lev.7, Kat. } \\
\text { No.45, (MÖ 8.-7. yüzy1l); Polat, 2002, Lev. 43, Çiz. B12, (MÖ geç 6.- erken 5. } \\
\text { yüzy1l); Yılmaz 2015, Lev. 17, Kat. No. 4, (MÖ 900-330); Duprê 1983, Pl 62, } \\
\text { Kat. No. 24, (MÖ 900-550). }\end{array}$}} \\
\hline & MÖ 8.-5. yüzyıl & & & & & & & \\
\hline
\end{tabular}

\begin{tabular}{|c|c|c|c|c|c|c|c|c|}
\hline \multirow{2}{*}{9} & Kazı Buluntu No. & Mal & Form & Bezeme & $\begin{array}{c}\text { Hamur } \\
\text { Rengi }\end{array}$ & Dış Rengi & İç Renk & A. Çap \\
\hline & $\begin{array}{c}19- \\
20 \mathrm{DE} / \mathrm{K} 20 / \mathrm{T} 1 / 443 \\
\end{array}$ & Kaba & Çanak & & 10 YR $6 / 2$ & $10 \mathrm{YR} 4 / 1$ & & 17.6 \\
\hline & Tanım & \multicolumn{7}{|c|}{$\begin{array}{l}\text { Ağız kenarı-gövde parçasıdır. İçe doğru kalınlaştırılmış ağızlı, içe dönük kenarlı } \\
\text { ve konik gövdelidir. İyi pişmiş, kabın hamuru kireç ve mika katkılıdır. }\end{array}$} \\
\hline & Referans-Dönem & \multirow{2}{*}{\multicolumn{7}{|c|}{$\begin{array}{l}\text { Durgu 2013, Lev. XIX, Kat No. 31, (MÖ 5.-4. yüzy1l); Bilgin 2018, Lev.7, Kat. } \\
\text { No.45, (MÖ 8.-7. yüzy1l); Polat, 2002, Lev. 43, Çiz. B12, (MÖ geç 6.- erken 5. } \\
\text { yüzy11); Y1lmaz 2015, Lev. 17, Kat. No. 4, (MÖ 900-330); Duprê 1983, Pl 62, } \\
\text { Kat. No. 24, (MÖ 900-550). }\end{array}$}} \\
\hline & MÖ 8.-5. yüzyıl & & & & & & & \\
\hline
\end{tabular}

\begin{tabular}{|c|c|c|c|c|c|c|c|c|}
\hline \multirow[b]{2}{*}{10} & Kazı Buluntu No. & Mal & Form & Bezeme & $\begin{array}{c}\text { Hamur } \\
\text { Rengi }\end{array}$ & Astar Rengi & $\begin{array}{c}\text { İç } \\
\text { Renk }\end{array}$ & $\begin{array}{l}\text { A. } \\
\text { Çap }\end{array}$ \\
\hline & $\begin{array}{c}19- \\
20 \mathrm{DE} / \mathrm{K} 20 / \mathrm{T} 1 / 444\end{array}$ & İyi & Çanak & - & 7.5 YR 4/1 & Gley 1 4/1 & - & 30.8 \\
\hline & Tanım & \multicolumn{7}{|c|}{$\begin{array}{l}\text { Ağız kenarı-gövde parçasıdır. İçe doğru kalınlaştırılmış ağızlı, içe dönük kenarlı } \\
\text { ve konik gövdelidir. İyi pişşş, kabın hamuru kireç ve mika katkılıdır. }\end{array}$} \\
\hline & Referans-Dönem & \multirow{2}{*}{\multicolumn{7}{|c|}{$\begin{array}{l}\text { Durgu 2013, Lev. XIX, Kat No. 31, (MÖ 5.-4. yüzy1l); Bilgin 2018, Lev.7, Kat. } \\
\text { No.45, (MÖ 8.-7. yüzy1); Polat, 2002, Lev. 43, Çiz. B12, (MÖ geç 6.- erken 5. } \\
\text { yüzy1l); Y1lmaz 2015, Lev. 17, Kat. No. 4, (MÖ 900-330); Duprê 1983, Pl 62, }\end{array}$}} \\
\hline & MÖ 8.-5. yüzyıl & & & & & & & \\
\hline
\end{tabular}


Kat. No. 24, (MÖ 900-550).

\section{(2.3.) Orta Demir Çağı Çanakları}

\begin{tabular}{|c|c|c|c|c|c|c|c|c|}
\hline \multirow[t]{2}{*}{1} & Kazı Buluntu No. & Mal & Form & Bezeme & $\begin{array}{c}\text { Hamur } \\
\text { Rengi }\end{array}$ & $\begin{array}{l}\text { Astar } \\
\text { Rengi } \\
\end{array}$ & İç Renk & A.Çap \\
\hline & 17EF/K47/T1/169 & İyi & Çanak & - & $2.5 \mathrm{YR} 6 / 2$ & $5 \mathrm{YR} 3 / 2$ & $10 \mathrm{YR} 5 / 3$ & 20.8 \\
\hline & Tanım & \multicolumn{7}{|c|}{$\begin{array}{l}\text { Ağız kenarı-gövde parçasıdır. Kalınlaştırılmış içe dönük ağız kenarlı, ağızdan } \\
\text { kaideye konik gövdeli, düzleştirilmiş yüzeylidir. İyi pişmiş, kabın hamuru kireç, } \\
\text { şamot ve mika katkılıdır. }\end{array}$} \\
\hline & ferans-Dönem & \multirow{2}{*}{\multicolumn{7}{|c|}{$\begin{array}{l}\text { Ergürer 2016, Lev. 23, No. 198, 199, (MÖ 6.-4. yüzy1l) (Tabaka III); Matsumura } \\
\text { 2005, Taf. 159, No. KL87-3103, KL87-3724, (Cronheit IIa6 IIc1) (MÖ 8.-6.yüzy1l); } \\
\text { Y1lmaz 2018, Lev. 40. No. 4, (MÖ 900-600). }\end{array}$}} \\
\hline & MÖ 8.-6. yüzyıl & & & & & & & \\
\hline
\end{tabular}

\begin{tabular}{|c|c|c|c|c|c|c|c|c|}
\hline \multirow[t]{2}{*}{2} & Kazı Buluntu No. & Mal & Form & Bezeme & $\begin{array}{c}\text { Hamur } \\
\text { Rengi }\end{array}$ & $\begin{array}{l}\text { Astar } \\
\text { Rengi } \\
\end{array}$ & $\begin{array}{c}\text { İç } \\
\text { Renk }\end{array}$ & A.Çap \\
\hline & 19-20DE/K20/T1/438 & Kaba & çanak & - & $10 \mathrm{YR} 5 / 2$ & $10 \mathrm{YR} 6 / 4$ & - & 34.6 \\
\hline & Tanım & \multicolumn{7}{|c|}{$\begin{array}{l}\text { Ağız kenarı-gövde parçasıdır. Kalınlaştırılmış içe dönük ağız kenarlı, ağızdan } \\
\text { kaideye konik gövdeli, düzleştirilmiş yüzeylidir. İyi pişmiş, kabın hamuru kireç, } \\
\text { şamot ve mika katkılıdır. }\end{array}$} \\
\hline & Referans-Dönem & \multirow{2}{*}{\multicolumn{7}{|c|}{$\begin{array}{l}\text { Ergürer 2016, Lev. 23, No. 198, 199, (MÖ 6.-4. yüzy1l) (Tabaka III); Matsumura } \\
\text { 2005, Taf. 159, No. KL87-3103, KL87-3724, (Cronheit IIa6 IIc1) (MÖ 8.-6.yüzy1l); } \\
\text { Y1lmaz 2018, Lev. 40. No. 4, (MÖ 900-600). }\end{array}$}} \\
\hline & MÖ 8.-6. yüzyıl & & & & & & & \\
\hline
\end{tabular}

\begin{tabular}{|c|c|c|c|c|c|c|c|c|}
\hline \multirow[t]{2}{*}{3} & Kazı Buluntu No. & Mal & Form & Bezeme & $\begin{array}{c}\text { Hamur } \\
\text { Rengi }\end{array}$ & $\begin{array}{l}\text { Astar } \\
\text { Rengi }\end{array}$ & İç Renk & A.Çap \\
\hline & 19E/K39/T1/246 & Kaba & Çanak & - & $2.5 \mathrm{Y} \mathrm{5/2}$ & $2.5 \mathrm{Y} 7 / 4$ & - & 20 \\
\hline & Tanım & \multicolumn{7}{|c|}{$\begin{array}{l}\text { Ağı kenarı-gövde parçasıdır. Kalınlaştırılmış içe dönük ağız kenarlı, ağızdan } \\
\text { kaideye konik gövdeli, düzleştirilmiş yüzeylidir. İyi pişmiş, kabın hamuru kireç, } \\
\text { şamot ve mika katkılıdır. }\end{array}$} \\
\hline & ferans-Dönem & \multirow{2}{*}{\multicolumn{7}{|c|}{$\begin{array}{l}\text { Ergürer 2016, Lev. 23, No. 198, 199, (MÖ 6.-4. yüzy1l) (Tabaka III); Matsumura } \\
\text { 2005, Taf. 159, No. KL87-3103, KL87-3724, (Cronheit IIa6 IIc1) (MÖ 8.-6.yüzy1); } \\
\text { Y1lmaz 2018, Lev. 40. No. 4, (MÖ 900-600). }\end{array}$}} \\
\hline & MÖ 8.-6. yüzyıl & & & & & & & \\
\hline
\end{tabular}

\begin{tabular}{|c|c|c|c|c|c|c|c|c|}
\hline 4 & Kazı Buluntu No. & Mal & Form & Bezeme & $\begin{array}{c}\text { Hamur } \\
\text { Rengi }\end{array}$ & Astar Rengi & $\begin{array}{c}\text { İç } \\
\text { Renk }\end{array}$ & A.Çap \\
\hline & 19-20-21E/K22/T1/731 & Kaba & Çanak & - & $2.5 \mathrm{Y} 4 / 2$ & Gley $13 / \mathrm{N}$ & - & 14.4 \\
\hline & Tanım & \multicolumn{7}{|c|}{$\begin{array}{l}\text { Ağız kenarı-gövde parçasıdır. Kalınlaştırılmış içe dönük ağız kenarlı, ağızdan } \\
\text { kaideye konik gövdeli, düzleştirilmiş yüzeylidir. İyi pişmiş, kabın hamuru kireç, } \\
\text { şamot ve mika katkılıdır. }\end{array}$} \\
\hline & $\begin{array}{c}\text { Referans-Dönem } \\
\text { MÖ 8.-6. yüzyıl }\end{array}$ & \multicolumn{7}{|c|}{$\begin{array}{l}\text { Ergürer 2016, Lev. 23, No. 198, 199, (MÖ 6.-4. yüzy1) (Tabaka III); Matsumura } \\
\text { 2005, Taf. 159, No. KL87-3103, KL87-3724, (Cronheit IIa6 IIc1) (MÖ 8.- } \\
\text { 6.yüzy1l); Y1lmaz 2018, Lev. 40. No. 4, (MÖ 900-600). }\end{array}$} \\
\hline
\end{tabular}




\section{(2.4.) Orta Demir Çağı Çanakları}

\begin{tabular}{|c|c|c|c|c|c|c|c|c|}
\hline \multirow[t]{2}{*}{1} & Kazi Buluntu No. & Mal & Form & Bezeme & $\begin{array}{c}\text { Hamur } \\
\text { Rengi }\end{array}$ & $\begin{array}{l}\text { Astar } \\
\text { Rengi }\end{array}$ & İç Renk & A.Çap \\
\hline & 17D/K11/T1/694 & İyi & Çanak & - & Gley $17 / \mathrm{N}$ & $2.5 \mathrm{Y} 4 / 1$ & $2.5 \mathrm{Y} 4 / 1$ & 16 \\
\hline & Tanım & \multicolumn{7}{|c|}{$\begin{array}{l}\text { Ağız kenarı-gövde parçasıdır. Çark yapımıdır. Dışa çekik ağız kenarlı olup ağızdan } \\
\text { omuza keskin bir geçişe sahiptir. Ağzının bir kısmı sağlam ele geçmiştir. İyi } \\
\text { pişmiş, sıkı dokulu, kabın hamuru kireç, taş, kuvars ve mika katkılıdır. }\end{array}$} \\
\hline & Referans-Dönem & \multirow{2}{*}{\multicolumn{7}{|c|}{$\begin{array}{l}\text { Ergürer 2016, Lev. 16, Kat. No. } 129 \text { (MÖ 8.-6. yüzy11); Bossert 2000, Taf 82/974 } \\
\text { (MÖ 7.-5. yüzy1l); Matsumura 2005, Taf. 156/KL 87-3798 (MÖ 600-580). }\end{array}$}} \\
\hline & MÖ 8.- 6. yüzyıl & & & & & & & \\
\hline
\end{tabular}

\begin{tabular}{|c|c|c|c|c|c|c|c|c|}
\hline \multirow[t]{2}{*}{2} & Kazı Buluntu No. & Mal & Form & Bezeme & $\begin{array}{c}\text { Hamur } \\
\text { Rengi }\end{array}$ & Astar Rengi & İç Renk & A.Çap \\
\hline & 17EF/K47/T4/186 & İyi & Çanak & - & 2.5 YR $5 / 8$ & $10 \mathrm{YR} 6 / 4$ & - & 23.5 \\
\hline & Tanım & \multicolumn{7}{|c|}{$\begin{array}{l}\text { Ağız kenarı-gövde parçasıdır. Çark yapımıdır. Dışa çekik ağız kenarlı olup ağızdan } \\
\text { omuza keskin bir geçişe sahiptir. Ağzının bir kısmı sağlam ele geçmiştir. İyi pişmiş, } \\
\text { sıkı dokulu, kabın hamuru kireç, taş, kuvars ve mika katkılıdır. }\end{array}$} \\
\hline & Referans-Dönem & \multirow{2}{*}{\multicolumn{7}{|c|}{$\begin{array}{l}\text { Ergürer 2016, Lev. 16, Kat. No. } 129 \text { (MÖ 8.-6. yüzy1l); Bossert 2000, Taf 82/974 } \\
\text { (MÖ 7.-5. yüzy11); Matsumura 2005, Taf. 156/KL 87-3798 (MÖ 600-580). }\end{array}$}} \\
\hline & MÖ 8. - 6. yüzyıl & & & & & & & \\
\hline
\end{tabular}

\section{Geç Demir Çağı Çanakları}

\begin{tabular}{|c|c|c|c|c|c|c|c|c|}
\hline \multirow[t]{2}{*}{1} & Kazı Bul & Mal & Form & Bezeme & $\begin{array}{c}\text { Hamur } \\
\text { Rengi }\end{array}$ & $\begin{array}{l}\text { Astar } \\
\text { Rengi }\end{array}$ & İç Renk & A.Çap \\
\hline & & & & - & 7.5 & & & 19 \\
\hline & 1 & \multicolumn{7}{|c|}{$\begin{array}{l}\text { A ğız kenarı-gövde parçasıdır. Yuvarlatılarak kalınlaştırılmış ağız kenarlı, } \\
\text { gövdeden kaideye konik gövdeli, benzer örnekleri düz diplidir. İyi pişmiş, kabın } \\
\text { hamuru kireç, taş ve mika katkılıdır. }\end{array}$} \\
\hline & ferans-Dönem & \multirow{2}{*}{\multicolumn{7}{|c|}{$\begin{array}{l}\text { Genz 2004, Taf. 38, Kat. No. 12, (MÖ 9.-6. yüzy1l); Matsumura 2005, Taf. 191, } \\
\text { Kat. No. KL86-1332, (MÖ 6.-5. yüzy1l); Bossert 2000, Taf. 65, Kat. No. 704, Taf. } \\
\text { 71, Kat. No. 803, (MÖ 9.-6. yüzy1l); Genz 2004, Taf. 40, Kat. No. 3, (MÖ 9.-6. } \\
\text { yüzyıl); Yılmaz 2018, lev. 40, Kat. No. 4, (MÖ 900-600/550). }\end{array}$}} \\
\hline & Ö 6.-5. y & & & & & & & \\
\hline
\end{tabular}

\begin{tabular}{|c|c|c|c|c|c|c|c|c|}
\hline \multirow[t]{2}{*}{2} & Kazı Buluntu No. & Mal & Form & Bezeme & $\begin{array}{l}\text { Hamur } \\
\text { Rengi }\end{array}$ & $\begin{array}{l}\text { Astar } \\
\text { Rengi }\end{array}$ & İç Renk & A.Çap \\
\hline & $20 \mathrm{E} / \mathrm{K} 10 / \mathrm{T} 4 / 676$ & İyi & Çanak & - & $5 \mathrm{Y} 3 / 1$ & $10 \mathrm{YR} 6 / 3$ & & 22.4 \\
\hline & Tanım & \multicolumn{7}{|c|}{$\begin{array}{l}\text { Ağız kenarı-gövde parçasıdır. Yuvarlatılarak kalınlaștırılmış ağız kenarlı, konik } \\
\text { gövdelidir. İyi pişmiş, kabın hamuru kireç, şamot ve mika katkılıdır. }\end{array}$} \\
\hline & Referans-Dönem & \multirow{2}{*}{\multicolumn{7}{|c|}{$\begin{array}{l}\text { Matsumura 2005, Taf. 191, Kat. No. KL86-1332, (MÖ 6.-5. yüzy1l); Bossert 2000, } \\
\text { Taf. 65, Kat. No. 704, Taf. 71, Kat. No. 803, (MÖ 9.-6. yüzyı1); Genz 2004, Taf. } \\
\text { 40, Kat. No. 3, (MÖ 9.-6. yüzyil). }\end{array}$}} \\
\hline & MÖ 6.-5. yüzyıl & & & & & & & \\
\hline
\end{tabular}

\begin{tabular}{|c|c|c|c|c|c|c|c|c|}
\hline \multirow[t]{2}{*}{3} & Kazı Buluntu No. & Mal & Form & Bezeme & $\begin{array}{c}\text { Hamur } \\
\text { Rengi }\end{array}$ & $\begin{array}{l}\text { Astar } \\
\text { Rengi }\end{array}$ & İç Renk & A.Çap \\
\hline & $19-20 \mathrm{DE} / \mathrm{K} 20 / \mathrm{T} 1 / 436$ & İyi & Çanak & - & 7.5 YR $5 / 3$ & Gley 14 & & 22.6 \\
\hline & Tanım & \multicolumn{7}{|c|}{$\begin{array}{l}\text { Ağız kenarı-gövde parçasıdır. Yuvarlatılarak kalınlaştırılmış ağız kenarlı, konik } \\
\text { gövdelidir. İyi pişmiş, kabın hamuru kireç, şamot ve mika katkılıdır. }\end{array}$} \\
\hline & Referans-Dönem & \multirow{2}{*}{\multicolumn{7}{|c|}{$\begin{array}{l}\text { Genz 2004, Taf. 38, Kat. No. 12, (MÖ 9.-6. yüzy1l); Matsumura 2005, Taf. 191, } \\
\text { Kat. No. KL86-1332, (MÖ 6.-5. yüzy11); Bossert 2000, Taf. 65, Kat. No. 704, } \\
\text { Taf. 71, Kat. No. 803, (MÖ 9.-6. yüzy1); Genz 2004, Taf. 40, Kat. No. 3, (MÖ } \\
\text { 9.-6. yüzy1); Y1lmaz 2018, lev. 40, Kat. No. 4, (MÖ 900-600/550). }\end{array}$}} \\
\hline & MÖ 6.-5. yüzyıl & & & & & & & \\
\hline
\end{tabular}




\begin{tabular}{|c|c|c|c|c|c|c|c|c|}
\hline \multirow[t]{2}{*}{4} & Kazi Buluntu No. & Mal & Form & Bezeme & $\begin{array}{c}\text { Hamur } \\
\text { Rengi }\end{array}$ & Astar Rengi & $\begin{array}{c}\text { İç } \\
\text { Renk }\end{array}$ & A.Çap \\
\hline & $20 \mathrm{E} / \mathrm{K} 10 / \mathrm{T} 4 / 675$ & İyi & Çanak & & $10 \mathrm{YR} 4 / 3$ & 7.5 YR $4 / 4$ & & 21.8 \\
\hline & Tanım & \multicolumn{7}{|c|}{$\begin{array}{l}\text { Ağız kenarı-gövde parçasıdır. Yuvarlatılarak kalınlaştırılmış ağız kenarlı, konik } \\
\text { gövdelidir. İyi pişmiş, kabın hamuru kireç, şamot ve mika katkılıdır. }\end{array}$} \\
\hline & Referans-Dönem & \multirow{2}{*}{\multicolumn{7}{|c|}{$\begin{array}{l}\text { Genz 2004, Taf. 38, Kat. No. 12, (MÖ 9.-6. yüzyı1); Matsumura 2005, Taf. 191, } \\
\text { Kat. No. KL86-1332, (MÖ 6.-5. yüzy11); Bossert 2000, Taf. 65, Kat. No. 704, Taf. } \\
\text { 71, Kat. No. 803, (MÖ 9.-6. yüzy1); Genz 2004, Taf. 40, Kat. No. 3, (MÖ 9.-6. } \\
\text { yüzy1l); Yılmaz 2018, lev. 40, Kat. No. 4, (MÖ 900-600/550). }\end{array}$}} \\
\hline & MÖ 6.-5. yüzyıl & & & & & & & \\
\hline
\end{tabular}

\begin{tabular}{|c|c|c|c|c|c|c|c|c|}
\hline \multirow[t]{2}{*}{5} & Kazi Buluntu No. & Mal & Form & Bezeme & $\begin{array}{l}\text { Hamur } \\
\text { Rengi }\end{array}$ & $\begin{array}{l}\text { Astar } \\
\text { Rengi }\end{array}$ & İç Renk & A.Çap \\
\hline & 19-20-21DE/K21/T3/524 & Kaba & Çanak & - & 2.5 Y $3 / 2$ & 7.5 YR $6 / 6$ & - & 16 \\
\hline \multicolumn{2}{|c|}{ Tanım } & \multicolumn{7}{|c|}{$\begin{array}{l}\text { Ağız kenarı-gövde parçasıdır. Yuvarlatılarak kalınlaştırılmış ağız kenarlı, konik } \\
\text { gövdelidir. İyi pişmiş, kabın hamuru kireç, şamot ve mika katkılıdır. }\end{array}$} \\
\hline \multicolumn{2}{|c|}{ Referans-Dönem } & \multirow{2}{*}{\multicolumn{7}{|c|}{$\begin{array}{l}\text { Genz 2004, Taf. 40, Kat. No. 7, (MÖ 9.-6. yüzy1l); Y1lmaz 2018, Lev. 5, Kat. No. } \\
\text { 3, (MÖ 900-600/550); Ergürer 2016, Lev. 26, Kat. No. 225, (MÖ 6.-4.yüzy11); } \\
\text { Matsumura 2005, Taf. 194, Kat. No. KL87-3162, (MÖ 6.-5. Yüzy11). }\end{array}$}} \\
\hline \multicolumn{2}{|c|}{ MÖ 6.-5. yüzyıl } & & & & & & & \\
\hline
\end{tabular}

\begin{tabular}{|c|c|c|c|c|c|c|c|c|}
\hline \multirow{2}{*}{6} & Kazı Buluntu No. & Mal & Form & Bezeme & $\begin{array}{c}\text { Hamur } \\
\text { Rengi }\end{array}$ & $\begin{array}{l}\text { Astar } \\
\text { Rengi }\end{array}$ & $\begin{array}{c}\text { İç } \\
\text { Renk }\end{array}$ & A.Çap \\
\hline & $\begin{array}{c}19- \\
20 \mathrm{DE} / \mathrm{K} 20 / \mathrm{T} 1 / 439 \\
\end{array}$ & Kaba & Çanak & - & $10 \mathrm{YR} 4 / 2$ & 10 YR 6/3 & & 26.2 \\
\hline & Tanım & \multicolumn{7}{|c|}{$\begin{array}{l}\text { Ağız kenarı-gövde parçasıdır. Yuvarlatılarak kalınlaştırılmış ağız kenarlı, konik } \\
\text { gövdelidir. İyi pişmiş, kabın hamuru kireç, şamot ve mika katkılıdır. }\end{array}$} \\
\hline & Referans-Dönem & \multirow{2}{*}{\multicolumn{7}{|c|}{$\begin{array}{l}\text { Genz 2004, Taf. 38, Kat. No. 12, (MÖ 9.-6. yüzy1l); Matsumura 2005, Taf. 191, } \\
\text { Kat. No. KL86-1332, (MÖ 6.-5. yüzy11); Bossert 2000, Taf. 65, Kat. No. 704, } \\
\text { Taf. 71, Kat. No. 803, (MÖ 9.-6. yüzy1); Genz 2004, Taf. 40, Kat. No. 3, (MÖ } \\
\text { 9.-6. yüzy1l); Y1lmaz 2018, lev. 40, Kat. No. 4, (MÖ 900-600/550). }\end{array}$}} \\
\hline & MÖ 6.-5. yüzyıl & & & & & & & \\
\hline
\end{tabular}

\begin{tabular}{|c|c|c|c|c|c|c|c|c|}
\hline \multirow[t]{2}{*}{7} & Kazı Buluntu No. & Mal & Form & Bezeme & $\begin{array}{c}\text { Hamur } \\
\text { Rengi }\end{array}$ & $\begin{array}{l}\text { Astar } \\
\text { Rengi }\end{array}$ & İç Renk & A.Çap \\
\hline & 19E/K39/T1/256 & İyi & Çanak & 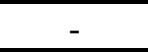 & $10 \mathrm{YR} 4 / 3$ & & $2.5 \mathrm{Y} 5 / 2$ & 18.4 \\
\hline & Tanım & \multicolumn{7}{|c|}{$\begin{array}{l}\text { Ağız kenarı-gövde parçasıdır. Yuvarlatılarak kalınlaştırılmış ağız kenarlı, konik } \\
\text { gövdelidir. İyi pişmiş, kabın hamuru kireç, şamot ve mika katkılıdır. }\end{array}$} \\
\hline & Referans-Dönem & \multicolumn{7}{|c|}{$\begin{array}{l}\text { Genz 2004, Taf. 38, Kat. No. 12, (MÖ 9.-6. yüzy11); Matsumura 2005, Taf. 191, } \\
\text { Kat. No. KL86-1332, (MÖ 6.-5. Yüzy1l). }\end{array}$} \\
\hline
\end{tabular}

\begin{tabular}{|c|c|c|c|c|c|c|c|c|}
\hline \multirow[t]{2}{*}{8} & Kazı Buluntu No. & Mal & Form & Bezeme & $\begin{array}{c}\text { Hamur } \\
\text { Rengi }\end{array}$ & $\begin{array}{l}\text { Astar } \\
\text { Rengi }\end{array}$ & İç Renk & A.Çap \\
\hline & $19-20 \mathrm{D} / \mathrm{K} 14 / \mathrm{T} 1 / 970$ & İyi & Çanak & - & $2.5 \mathrm{Y} 4 / 2$ & 2.5 Y $5 / 2$ & - & 28 \\
\hline & Tanım & \multicolumn{7}{|c|}{$\begin{array}{l}\text { Ağız kenarı-gövde parçasıdır. Yuvarlatılarak kalınlaştırılmış ağız kenarlı, konik } \\
\text { gövdelidir. İyi pişmiş, kabın hamuru kireç, şamot ve mika katkılıdır. }\end{array}$} \\
\hline & Referans-Dönem & \multirow{2}{*}{\multicolumn{7}{|c|}{$\begin{array}{l}\text { Genz 2004, Taf. 38, Kat. No. 12, (MÖ 9.-6. yüzy1l); Matsumura 2005, Taf. 191, } \\
\text { Kat. No. KL86-1332, (MÖ 6.-5. yüzy1l); Bossert 2000, Taf. 65, Kat. No. 704, } \\
\text { Taf. 71, Kat. No. 803, (MÖ 9.-6. yüzy11); Genz 2004, Taf. 40, Kat. No. 3, (MÖ } \\
\text { 9.-6. yüzy1l); Yılmaz 2018, lev. 40, Kat. No. 4, (MÖ 900-600/550). }\end{array}$}} \\
\hline & MÖ 6.-5. yüzyıl & & & & & & & \\
\hline
\end{tabular}

\begin{tabular}{|c|c|c|c|c|c|c|c|c|}
\hline \multirow{2}{*}{9} & Kazı Buluntu No. & Mal & Form & Bezeme & $\begin{array}{c}\text { Hamur } \\
\text { Rengi }\end{array}$ & $\begin{array}{c}\text { Astar } \\
\text { Rengi }\end{array}$ & İç Renk & A.Çap \\
\cline { 2 - 8 } & $13 \mathrm{G} / \mathrm{K} 30 / \mathrm{T} 1 / 857$ & Kaba & Çanak & & 10 YR 5/4 & 5 YR 6/6 & & 21 \\
\hline
\end{tabular}




\begin{tabular}{|c|c|}
\hline Tanım & $\begin{array}{l}\text { Ağız kenarı-gövde parçasıdır. Yuvarlatılarak kalınlaştırılmış ağız kenarlı, konik } \\
\text { gövdelidir. İyi pişmiş, kabın hamuru kireç, şamot ve mika katkılıdır. }\end{array}$ \\
\hline Referans-Dönem & \multirow{2}{*}{$\begin{array}{l}\text { Genz 2004, Taf. 38, Kat. No. 12, (MÖ 9.-6. yüzyıl); Matsumura 2005, Taf. 191, } \\
\text { Kat. No. KL86-1332, (MÖ 6.-5. yüzy1); Bossert 2000, Taf. 65, Kat. No. 704, Taf. } \\
\text { 71, Kat. No. 803, (MÖ 9.-6. yüzy1l); Genz 2004, Taf. 40, Kat. No. 3, (MÖ 9.-6. } \\
\text { yüzy1l); Y1lmaz 2018, lev. 40, Kat. No. 4, (MÖ 900-600/550). }\end{array}$} \\
\hline MÖ 6.-5. yüzyıl & \\
\hline
\end{tabular}

\begin{tabular}{|c|c|c|c|c|c|c|c|c|}
\hline \multirow[t]{2}{*}{10} & Kazı Buluntu No. & Mal & Form & Bezeme & $\begin{array}{l}\text { Hamur } \\
\text { Rengi }\end{array}$ & $\begin{array}{l}\text { Astar } \\
\text { Rengi }\end{array}$ & İç Renk & A.Çap \\
\hline & $20 \mathrm{~F} / \mathrm{K} 8 / \mathrm{T} 1$ & İyi & Çanak & & Gley $14 / \mathrm{N}$ & Gley $15 / \mathrm{N}$ & & 30 \\
\hline & Tanım & \multicolumn{7}{|c|}{$\begin{array}{l}\text { Ağız kenarı-gövde parçasıdır. Yuvarlatılarak kalınlaştırılmış ağız kenarlı, konik } \\
\text { gövdelidir. İyi pişmiş, kabın hamuru kireç, şamot ve mika katkılıdır. }\end{array}$} \\
\hline & ferans-Dönem & \multirow{2}{*}{\multicolumn{7}{|c|}{$\begin{array}{l}\text { Genz 2004, Taf. 38, Kat. No. 12, (MÖ 9.-6. yüzy1l); Matsumura 2005, Taf. 191, } \\
\text { Kat. No. KL86-1332, (MÖ 6.-5. yüzy1l); Bossert 2000, Taf. 65, Kat. No. 704, Taf. } \\
\text { 71, Kat. No. 803, (MÖ 9.-6. yüzy11); Genz 2004, Taf. 40, Kat. No. 3, (MÖ 9.-6. } \\
\text { yüzy1l); Y1lmaz 2018, lev. 40, Kat. No. 4, (MÖ 900-600/550). }\end{array}$}} \\
\hline & Ö 6.-5. yüzyıl & & & & & & & \\
\hline
\end{tabular}

\begin{tabular}{|c|c|c|c|c|c|c|c|c|}
\hline \multirow{2}{*}{11} & Kazı Buluntu No. & Mal & Form & Bezeme & $\begin{array}{c}\text { Hamur } \\
\text { Rengi }\end{array}$ & $\begin{array}{l}\text { Astar } \\
\text { Rengi } \\
\end{array}$ & İç Renk & A.Çap \\
\hline & $\begin{array}{c}19- \\
\text { 20D/K14/T12/1012 }\end{array}$ & İyi & Çanak & & $\begin{array}{c}\text { Gley } 1 \\
6 / N\end{array}$ & \multicolumn{2}{|l|}{ Gley $15 / 10 \mathrm{Y}$} & 18 \\
\hline & Tanım & \multicolumn{7}{|c|}{$\begin{array}{l}\text { Ağız kenarı-gövde parçasıdır. Yuvarlatılarak kalınlaştırılmış ağız kenarlı, konik } \\
\text { gövdelidir. İyi pişmiş, kabın hamuru kireç, şamot ve mika katkılıdır. }\end{array}$} \\
\hline & Referans-Dönem & \multirow{2}{*}{\multicolumn{7}{|c|}{$\begin{array}{l}\text { Y1lmaz 2018, Lev. 5, Kat. No. } 3 \text { (MÖ 900-600/550); Genz 2004, Taf. 40, Kat. } \\
\text { No. 7, (MÖ 9.-6. yüzy1l);Matsumura 2005, Taf. 194, Kat. No. KL87-3162 (MÖ } \\
\text { 6.-5. yüzyıl); Ergürer 2016, Lev.26, Kat. No. } 225 \text { (MÖ 6.-4.yüzyıl). }\end{array}$}} \\
\hline & MÖ 6.-5. yüzyıl & & & & & & & \\
\hline
\end{tabular}

\begin{tabular}{r|c|c|c|c|c|c|c|c|}
\hline \multirow{2}{*}{12} & Kazı Buluntu No. & Mal & Form & Bezeme & $\begin{array}{c}\text { Hamur } \\
\text { Rengi }\end{array}$ & $\begin{array}{c}\text { Astar } \\
\text { Rengi }\end{array}$ & $\begin{array}{c}\text { Íç } \\
\text { Renk }\end{array}$ & A.Çap \\
\cline { 2 - 7 } & $19-20 D / K 14 / T 1 / 981$ & Kaba & Çanak & - & 7.5 YR 5/2 & Gley 1 4/N & - & 24 \\
\hline
\end{tabular}

\begin{tabular}{|c|c|c|c|c|c|c|c|c|}
\hline \multirow{2}{*}{13} & Kazı Buluntu No. & Mal & Form & Bezeme & $\begin{array}{c}\text { Hamur } \\
\text { Rengi }\end{array}$ & $\begin{array}{l}\text { Astar } \\
\text { Rengi }\end{array}$ & İç Renk & A.Çap \\
\hline & $\begin{array}{c}19- \\
20 \mathrm{DE} / \mathrm{K} 20 / \mathrm{T} 1 / 455\end{array}$ & İyi & Çaı & - & $10 \mathrm{YR} 4 / 2$ & $2.5 \mathrm{Y} 4 / 1$ & - & 20.2 \\
\hline & Tanım & \multicolumn{7}{|c|}{$\begin{array}{l}\text { Ağız kenarı-gövde parçasıdır. Yuvarlatılarak kalınlaştırılmış ağız kenarlı, konik } \\
\text { gövdelidir. İyi pişmiş, kabın hamuru kireç, şamot ve mika katkılıdır. }\end{array}$} \\
\hline & ferans-Dönem & \multirow{2}{*}{\multicolumn{7}{|c|}{$\begin{array}{l}\text { Genz 2004, Taf. 40, Kat. No. 7, (MÖ 9.-6. yüzy1l); Yılmaz 2018, Lev. 5, Kat. } \\
\text { No. 3, (MÖ 900-600/550); Ergürer 2016, Lev. 26, Kat. No. 225, (MÖ 6.- } \\
\text { 4.yüzy11); Matsumura 2005, Taf. 194, Kat. No. KL87-3162, (MÖ 6.-5. Yüzy1l). }\end{array}$}} \\
\hline & MÖ 6.-5. yüzyıl & & & & & & & \\
\hline
\end{tabular}


LEVHALAR

Levha 1

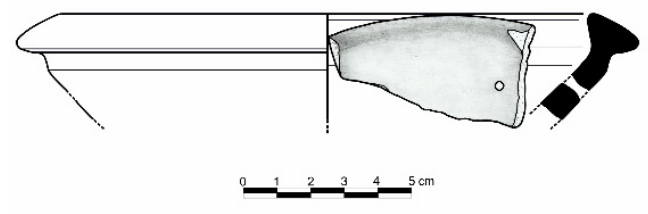

1

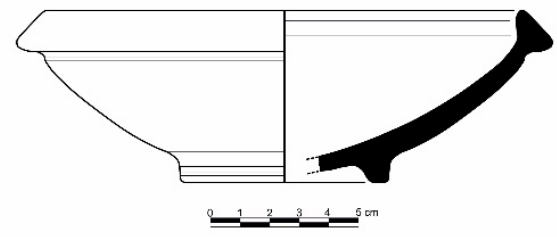

2

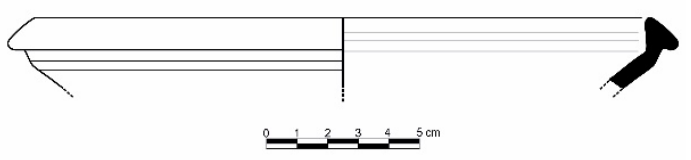

3

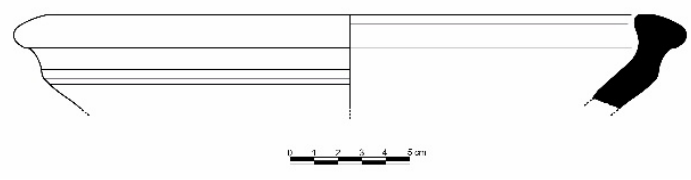

4

Levha 2

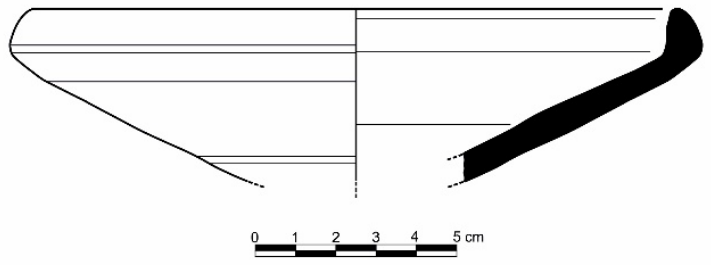

5

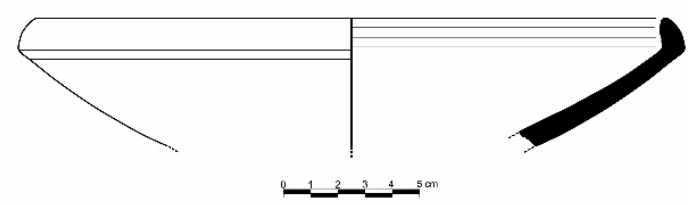

6 


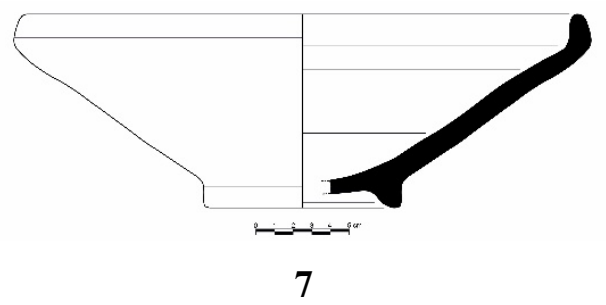

Ölçek $1 / 2$

Levha 3
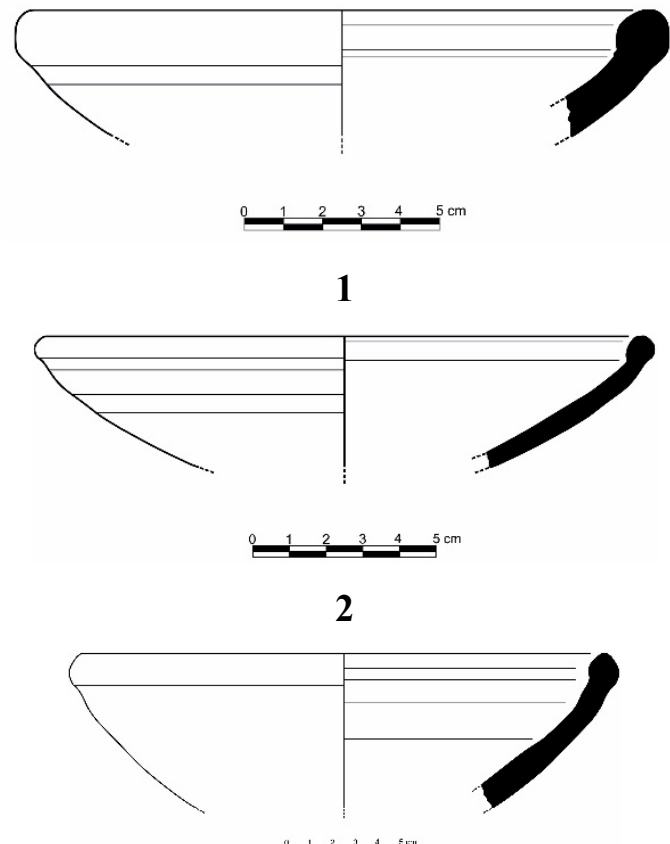

3

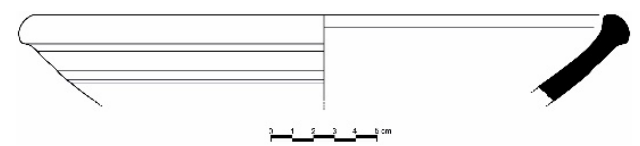

4

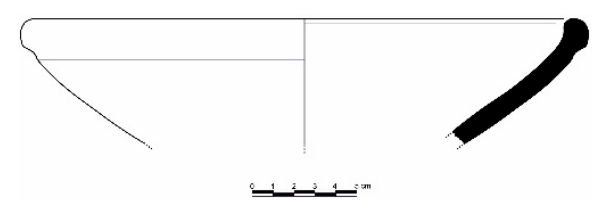

5

Ölçek ${ }^{1 / 2}$

Levha 4 

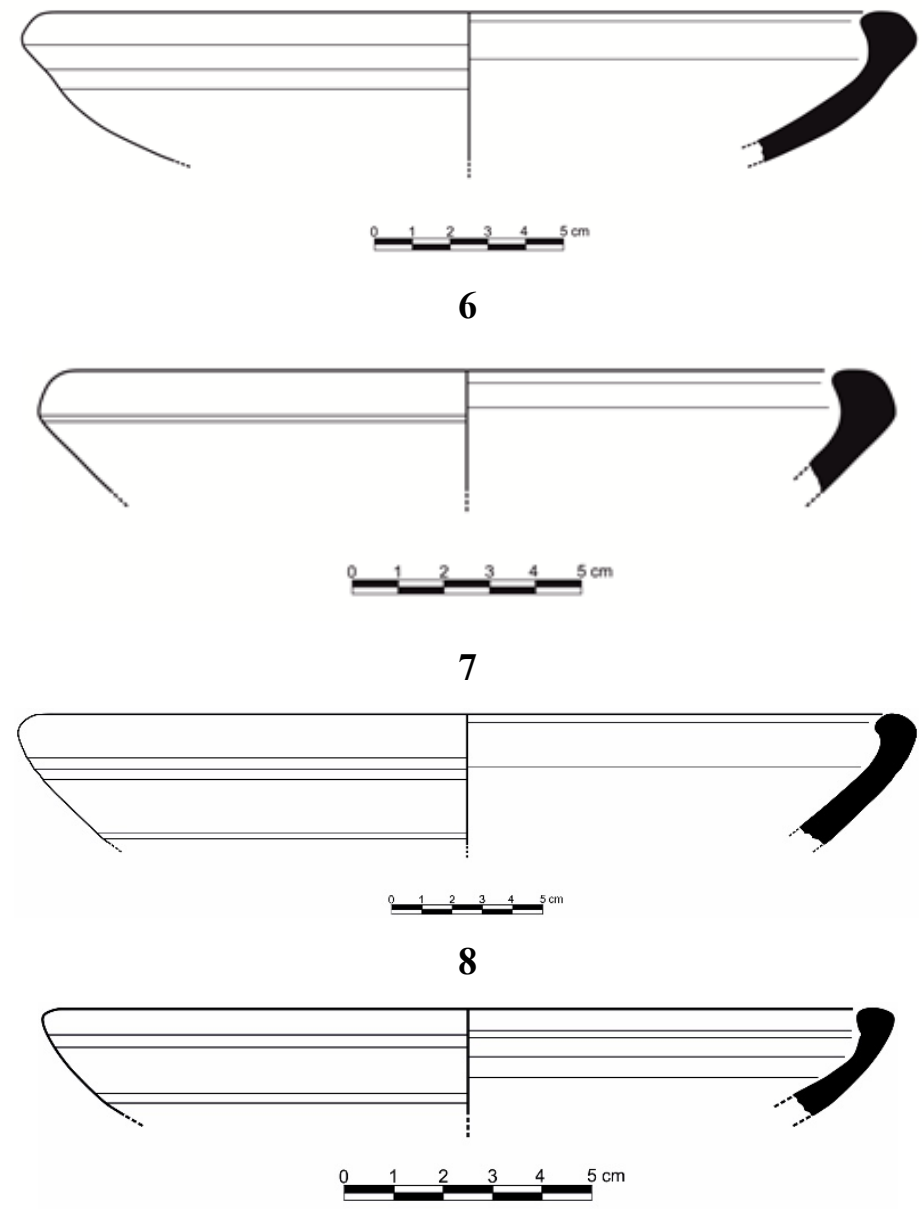

9
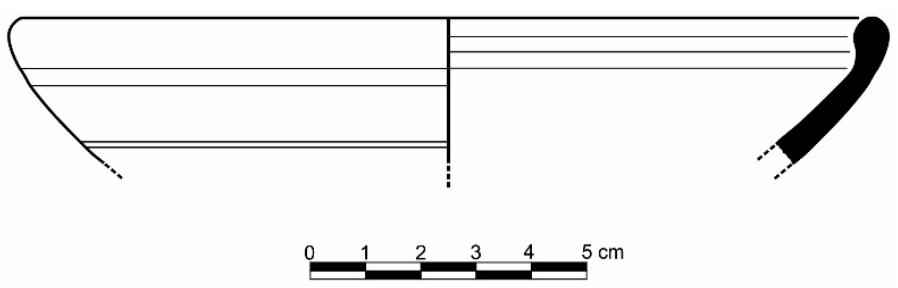

10

Ölçek $1 / 2$

Levha 5

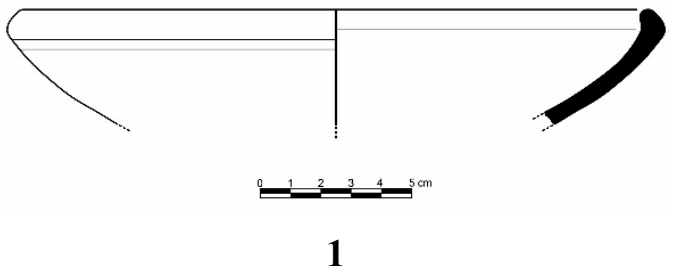




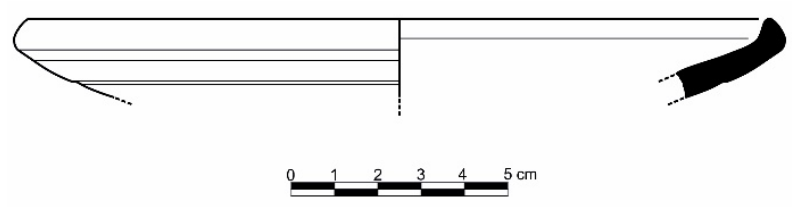

2

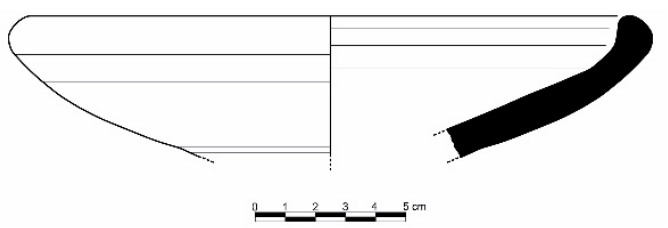

3

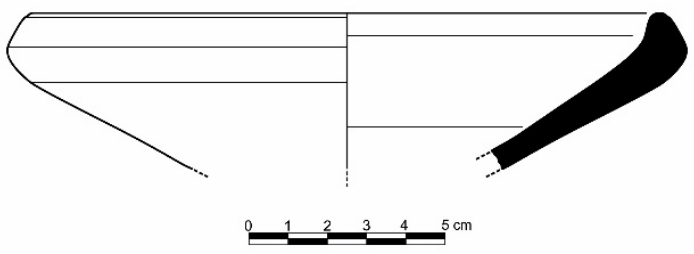

4

Levha 6
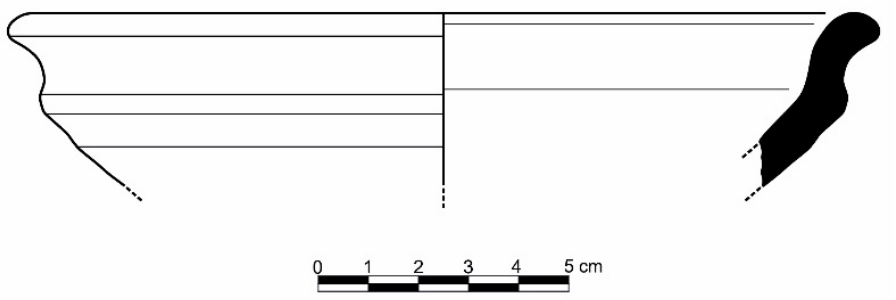

1

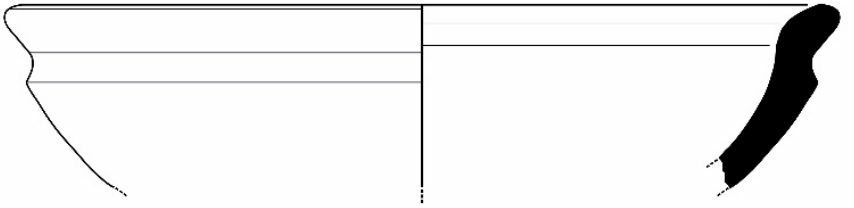

$=2-3=0$

2

Ölçek 1/2

Levha 7

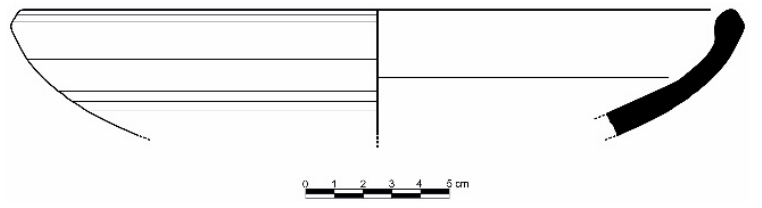

Turkish Studies - History, 15(2) 

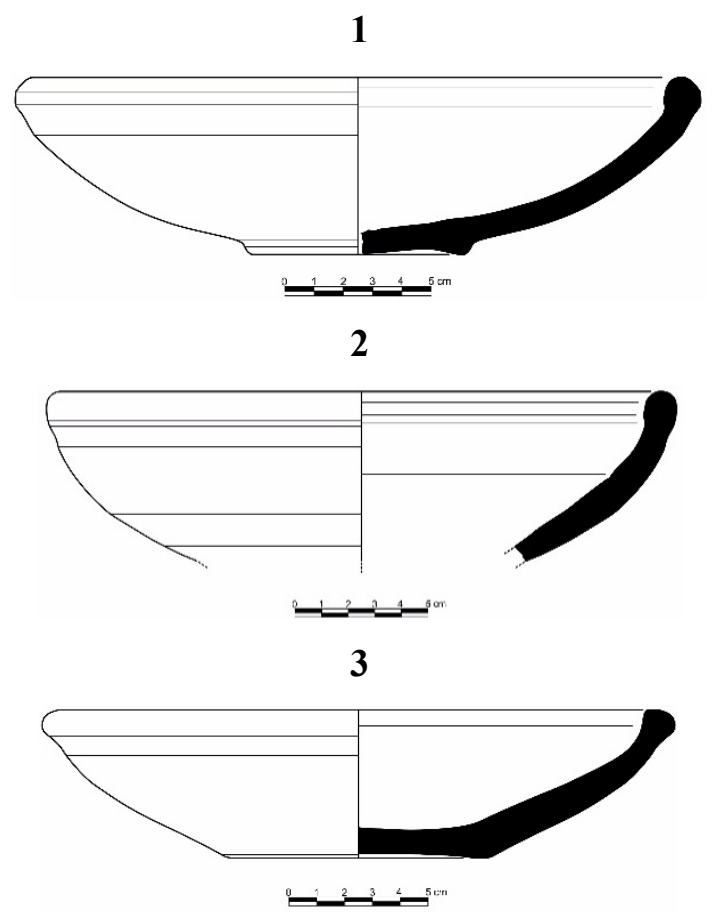

4

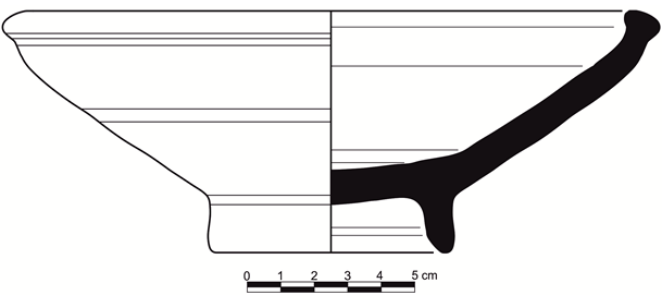

5
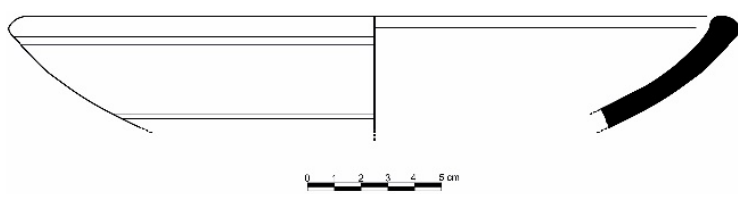

6
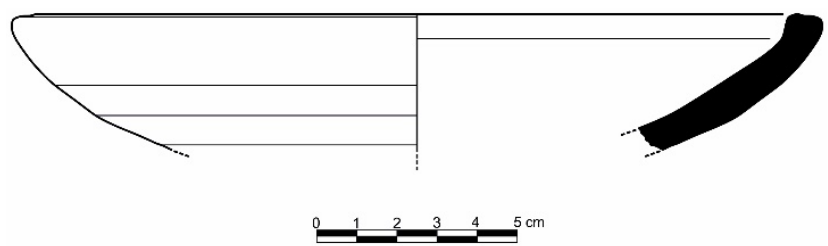

7

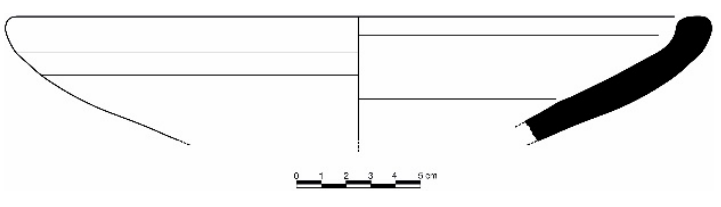

8 


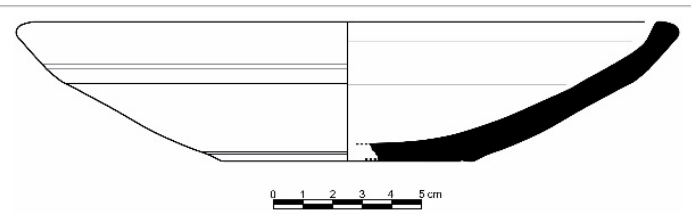

9
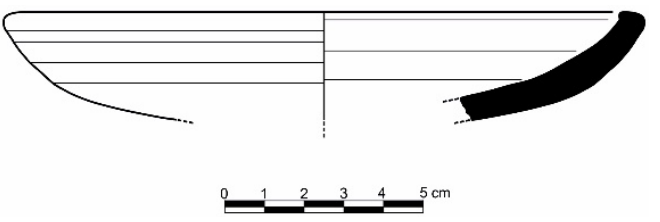

10

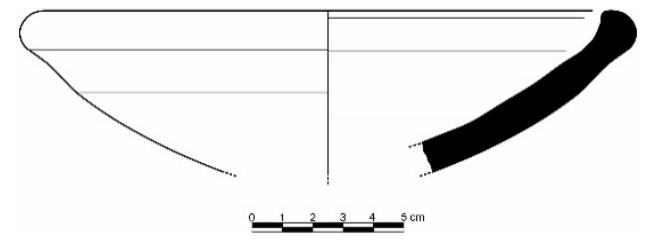

11

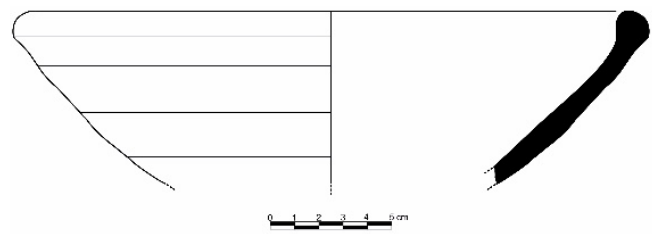

12

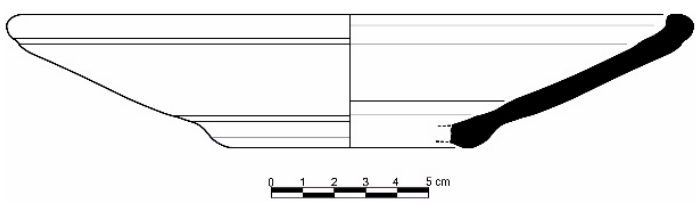

13

Ölçek ${ }^{1 / 2}$ 